\title{
Políticas de acumulación patrimonial y construcción de poder en el siglo XV: el linaje de María de Ávila
}

\section{Policies of patrimonial accumulation and construction of power in the fif- teenth century: the lineage of Maria de Avila}

\author{
Corina LuCHÍA \\ Universidad de Buenos Aires-CONICET
}

\begin{abstract}
RESUMEN
En el presente estudio reconcentrado fundamentalmente sobre la documentación que provee el linaje abulense de los Dávila se pretende reconocer las diferentes estrategias de acumulación patrimonial y su articulación con los distintos vínculos políticos, por medio del seguimiento de la actuación de María de Ávila, tanto como miembro de su linaje de origen como en conjunto con las acciones que emprenden sus sucesivos esposos. La ampliación patrimonial que se constata documentalmente desde las últimas décadas del siglo XV y su fuerte lazo con la monarquía católica permite comprender la dinámica de las oligarquías urbanas y el constante proceso de promoción y ascenso de los sectores más encumbrados de ellas, hasta alcanzar posiciones dentro de una nobleza de rango medio en el área, con proyecciones sobre otras villas cercanas. El trabajo de los documentos que exhiben las numerosas operaciones, que incluyen distintas modalidades de traspaso, cesión y compra de suelos posibilita advertir las prácticas, múltiples y complejas, que desarrollan los linajes de la ciudad de Ávila para fortalecer su poder patrimonial, político y su prestigio social.
\end{abstract}

Palabras clave: Linaje. Patrimonio. Poder. Ávila. Siglo XV

\begin{abstract}
This paper concentrated primarily on the documentation provided in the lineage of Avila Davila is to recognize the different strategies of wealth accumulation and its relationship with the various political, by monitoring the performance of Maria de Avila, both as a member of their lineage of origin and in conjunction with the subsequent actions that they take their husbands. Enlargement documentary heritage which is apparent from the last decades of the Xvth century and its strong ties to the catholic monarchy to understand the dynamics of urban oligarchies and the continuing process of promotion and advancement of the most exalted of them, to reach positions within a middle-ranking nobility in the area, with projections of other nearby villages. The work of the documents that show the many operations, including various forms of transfer, disposal and possible land purchase warn practices, multiple and complex, developing lineages of the city of Avila to strengthen its patrimonial power, political and social prestige.
\end{abstract}

Keywords: Lineage. Heritage. Power. Ávila. 15th Century

Sumario: 1. Una reseña general de los grandes propietarios abulenses en el siglo Xv. 2. María de Ávila: Hija, esposa, viuda: gran propietaria. 3. Linaje, patrimonio y vínculos políticos. 4. María de Ávila: Matrimonio, patrimonio, poder. 5. Poder de origen, poder de alianza. 6 . Reflexiones finales para una agenda de trabajo futura. Anexo. 
La solidez patrimonial de los principales linajes de la ciudad de Ávila en los últimos siglos medievales, con particular énfasis en el siglo XV, se exhibe de manera elocuente en la amplia documentación que se conserva de este importante concejo. Caballeros villanos que han logrado consolidar posiciones de poder económico y político sobre la Tierra, junto a miembros destacados de la nobleza menor del lugar, de la que muchos de los primeros participan, conforman una clase de ricos y a la vez poderosos propietarios que controlan la dinámica económica, social y política de la región.

Las múltiples prácticas a través de las cuales los miembros de las familias más preeminentes conforman a lo largo de los siglos extensos patrimonios, cuyas características veremos más adelante, configuran una estrategia que adquiere no sólo rasgos económicos sino que le otorga a los diferentes grupos parentales mejores condiciones para su actuación política en el nivel local del reino'. Las ocupaciones masivas de las tierras colectivas, la violación permanente de las costumbres campesinas, así como el hábil aprovechamiento de coyunturas de crisis y de la recurrente vulnerabilidad de los aldeanos, también inciden en el constante flujo de suelos hacia los sectores de poder abulenses ${ }^{2}$. Compras, arrendamientos, traspasos que encierran complejos mecanismos de inserción en las aldeas, forman la contracara legal de aquéllas otras acciones abiertamente contrarias a los usos legítimos de la Tierra y sus gentes.

En el lento proceso a través del cual se va forjando la riqueza de los linajes, también influyen las favorables relaciones que entretejen con el poder regio ${ }^{3}$, ocupando muchos cargos, de desigual importancia, dentro de la administración monárquica ${ }^{4}$. Esta situación, que excede el caso abulense, se extiende a las principales ciudades castellanas, en las cuales bajo el reinado de los Reyes Católicos, pareciera reactivarse, no sin contradicciones, el proceso de consolidación de los gobiernos oligárquicos 5 .

1 "Los linajes resultan instrumentos eficacísimos para controlar las esferas de poder local, por lo que son también utilizados por la Corona", del VAL VALDIVIESO, M. I., "Ascenso social y lucha por el poder en las ciudades castellanas del siglo XV”, En la España Medieval, 17, 1994, pp. 157-184, 1994.

${ }^{2}$ Estas cuestiones las hemos trabajado, entre otros, en "Poderes locales, monarquía y propiedad comunal en los concejos de realengo castellanos, bajomedievales, Anales de la Universidad de Alicante. Historia Medieval, 15, 2006-2008, pp. 215-237; "Los pleitos por los términos comunales en el concejo de Ciudad Rodrigo en la Baja Edad Media”, Historia. Instituciones. Documentos, 35, 2008, pp. 269-290; "Políticas monárquicas frente a la propiedad comunal en los concejos de realengo castellanos bajomedievales", Hispania, vol. LXVIII, 230, 2008, pp. 619-645.

3 "Lo que confirió una posición de preeminencia socioeconómica a estas noblezas de rango medio [es] que dedicaban la mayor parte de su tiempo al servicio de los reyes, como embajadores, corregidores, tenentes de fortalezas, capitanes de tropas, cortesanos, etc", PASCUA ECHEGARARY, E., "Las otras comunidades: Pastores y ganaderos en Castilla Medieval", en Rodríguez, A (Ed) El Lugar del campesino . En torno a la obra de Reyna Pastor, PUV, Valencia, 2007, pp. 209-237, esp. 229.

${ }^{4}$ Como ha indicado en el clásico estudio el profesor Salvador de Moxó, para la nobleza castellana del siglo XIV, patrimonio, privanza y nacimiento, parecieran ser los tres elementos que se conjugan en desigual medida para conformar las cualidades del grupo nobiliario castellano. La centuria siguiente, modificará el balance entre los tres componentes, véase de MOXÓ, S., "La nobleza castellana en el siglo XIV", Anuario de Estudios Medievales, 7, 1970-1971, pp. 494-497.

${ }^{5}$ Véase DIAGO HERNANDO, M., "Las corporaciones de caballeros hidalgos en las ciudades castellanas a fines de la Edad Media. Su participación en el ejerció del poder local”, Anuario de estudios Medievales, 36/2, 2006, pp. 803-838, esp. 813. 
En la indagación erudita de las actuaciones patrimoniales de los principales propietarios descubrimos los vínculos con el poder político superior, con los aparatos políticos municipales y fundamentalmente, la dinámica que adquiere la propia elite dominante en la villa. En particular, nos referimos a la movilidad entre las diferentes ramas de un mismo linaje, las proyecciones que distintos de sus miembros logran fuera del concejo abulense ${ }^{6}$, como es el caso de las numerosas adquisiciones en la tierra de Segovia, y la "rivalidad colaborante" tanto entre parentelas extensas, como entre sus integrantes.

Los sectores más encumbrados de la región, cuyos orígenes se remontan a los tiempos de la repoblación tardía emprendida por Alfonso X, van adquiriendo a partir de un modesto patrimonio, amplias extensiones de tierras que gozarán progresivamente de sus respectivas jurisdicciones, por concesión regia o bien por apropiación de hecho de las mismas ${ }^{7}$. Entre estos grupos, la estirpe de los Dávila es, junto con los miembros de la casa de Cespedosa y de Villafranca y las Navas ${ }^{8}$, uno de los casos de mayor interés, por la dimensión e incidencia de sus actuaciones, tanto en Ávila como fuera de ella. Descendiente de este grupo, María de Ávila, constituye un personaje de singular relevancia si seguimos su trayectoria, no como biografía individual, sino como parte de la trama de acciones estratégicas de los sectores privilegiados abulenses, que incluyen alianzas matrimoniales favorables, hábiles operaciones inmobiliarias, acceso a cargos y oficios decisivos.

Los caballeros villanos, originarios defensores de áreas de frontera, van conformando progresivamente poderes patrimoniales y en algunas ocasiones, atribuciones de orden jurisdiccional, como se advierte con claridad en muchos de los miembros que conforman una dinámica nobleza local de rango medio ${ }^{9}$. La cualidad privilegiada de los grupos aquí estudiados orienta la indagación hacia los vínculos que se establecen entre sectores de la alta nobleza castellana, incluyendo a la propia monarquía, y grupos menores locales, en cuya articulación comienza a descubrirse la construcción, hacia el siglo XV, de verdaderos poderes jurisdiccionales privados ${ }^{10}$.

${ }^{6}$ Véase el interesante estudio de caso sobre un caballero abulense, MORENO NÚÑEZ, J. I., "El caballero abulense Fernán Blázquez y el nacimiento de un señorío toledano del siglo XIV: San Román del Monte", En la España Medieval, vol. 23, 2000, pp. 117-135.

${ }^{7}$ Respecto del extenso linaje de los Dávila, Moreno Núñez señala: "logran formar un importante patrimonio señorial de rango local y ejercer puestos descollantes en la administración central como colaboradores directos del Rey", ibídem, "Los Dávila, linaje de caballeros abulenses. Contribución al estudio de la nobleza castellana en la Baja Edad Media", En la España Medieval, vol. 3, 1982, pp. 157-172, esp. 157.

${ }^{8}$ Quien recibe tempranamente por privilegio de Alfonso X en 1256 dicho señorío, luego en 1389 se encuentra un pergamino que da cuenta de una carta ejecutoria sobre el mayorazgo y unas casas fuertes en el lugar a favor de este personaje, Archivo Real Cancillería de Valladolid, Colección Pergaminos, Carpeta 17,9, ibídem, 17, 10 .

${ }^{9}$ Sobre la caracterización de la caballería villana véase ASTARITA, C., "Los caballeros villanos", Del Feudalismo al capitalismo. Cambio social y político en Castilla y Europa occidental, 1250-1520, PUV, 2005, pp. 29-66.

10 "Por supuesto no todas las regiones de la Corona de Castilla experimentaron entonces una idéntica evolución, sino que, a juzgar por los resultados de los trabajos de investigación dados a conocer hasta el momento, hubo unas en que la capacidad de control del territorio por parte de la monarquía fue mayor, y otras en que la nobleza consiguió ejercer un dominio casi absoluto. Desde una perspectiva global, no 
El caso de Ávila es de particular interés, dado que a diferencia de lo ocurrido en otras regiones, la mayoría de los miembros de la pequeña nobleza rural pertenecen a las oligarquías urbanas, que a partir de su propia consolidación como grandes propietarios y a su control del gobierno concejil, logran vincularse con los linajes nobiliarios más poderosos del reino. Otro elemento que en la ciudad gravita y es fuente de acuerdos y de tensiones recurrentes, es la presencia de fuertes instituciones eclesiásticas con las cuales María de Ávila mantendrá estrechas relaciones hacia el final de su vida ${ }^{1}$.

La riqueza de la documentación del linaje de Doña María de Ávila en el siglo $\mathrm{XV}^{12}$, nos permite concentrar el estudio en una de las familias más representativas, aunque se harán permanentes referencias a integrantes de otros grupos parentales destacados de la villa, con quienes guardan cercanas y contradictorias relaciones de colaboración y competencia ${ }^{13}$. El carácter homogéneo de la base erudita que sostiene este trabajo, permite apreciar los rasgos más distintivos de este personaje; a la vez que esbozar las cualidades sociológicas del grupo al que pertenece. En este sentido, en las páginas que siguen no se estudiará la situación de María de Ávila desde la perspectiva del caso individual, sino como parte de la evolución política, social y económica de los linajes urbanos de la ciudad.

Por último, es necesario delimitar aquéllas cuestiones que, no por carecer de importancia, serán desplazadas de los objetivos centrales de esta contribución. Para ello debemos justificar la explícita exclusión de su tratamiento específico. En primer lugar, el trabajo pretende articular el seguimiento de un personaje singular como parte del desarrollo del linaje del que procede. No se trata de un estudio de las relaciones de parentesco, para lo cual la existencia de prolíficos trabajos sobre el tema da sustento a muchas de estas reflexiones ${ }^{14}$.

obstante, puede afirmarse que en determinados momentos del siglo XV, la Corona de Castilla estuvo bastante cerca de quedar reducida a una suerte de federación de regiones sometidas a la nobleza", DIAGO HERNANDO, M., "El poder de la nobleza en los ámbitos regionales de la Corona de Castilla a fines del Medioevo, Las estrategias políticas de los grandes linajes en La Rioja hasta la revuelta comunera", Hispania, Revista de Historia, Vol. 66, 223, 2006, pp. 501-546.

${ }^{11}$ Entre otros Monsalvo Antón alude a la fuerte presencia espacial de estas instituciones en el ámbito abulense en "Los espacios de poder en la ciudad medieval: Impresiones a partir de cuatro casos: León, Burgos, Ávila y salamanca", de la Iglesia Duarte, J. I. (Coord); Martín Rodríguez, J. L. (Dir), Los espacios de poder en la España Medieval: XII Semana de estudios medievales, Nájera, 2001, pp. 97-147.

${ }^{12}$ VVAA, Un linaje abulense en el siglo XV: Doña María de Ávila. (Documentación medieval del monasterio de las Gordillas), Institución Gran Duque de Alba, Vol. I a IV, 1997-98. (DMMLG)

${ }^{13}$ Centraremos el trabajo en las últimas décadas del siglo Xv, etapa de mayor actividad de los personajes que relevamos en este estudio.

${ }^{14}$ Sobre la funcionalidad política del linaje como institución de gobierno, desde una perspectiva comparativa, DIAGO HERNANDO, M., "El papel de los linajes en las estructuras de gobierno urbano en Castilla y en el Imperio Alemán durante los siglos bajomedievales”, En la España medieval, 20, 1997, pp. 143-177. La transformación desde la organización privada de los grandes propietarios hacia su institucionalización como subestructura política con funciones de gobierno es reconocida por Monsalvo Antón: "la metamorfosis de una 'institución social y privada' de la clase dominante urbana, esto es, las estructuras de linaje, en una 'institución política', idónea así para el reciclaje permanente de los cuadros dirigentes. Por ello propició, desde el siglo XIV, la institucionalización de las estructuras de linaje en relación con el 
En segundo término, la singularidad de María de Ávila, posibilita interpretaciones desde una perspectiva de género, dada su condición de mujer y dos veces viuda y activa protagonista de muchas de las prácticas que conforman el poder de las elites dominantes. Los estudios sobre el papel de las mujeres en la sociedad castellana bajomedieval y en particular la caracterización de las viudas, son una referencia insoslayable, aunque se alejan del objetivo que persiguen estas líneas ${ }^{15}$. En este sentido, no proponemos estudiar a María de Ávila como el caso "típico" de la mujer ennoblecida por matrimonio, ni tampoco como expresión de la condición de las mujeres dentro de las elites concejiles. De modo tentativo, la observamos inicialmente como quien proviniendo de los estamentos privilegiados locales accede a posiciones de relevancia dentro de la dinámica política que imprimen al reino los Reyes Católicos.

La propuesta de este trabajo es más modesta y deja abierta la posibilidad de emprender futuras investigaciones que puedan encarar de modo específico los aspectos mencionados. Se trata de recorrer la evolución de la situación patrimonial de María y de sus vínculos políticos desde su origen, como miembro de un destacado linaje abulense hasta su vinculación tutelar con el poder de los soberanos y su ocaso al ingreso en un monasterio, por ella fundado, como parte de la recurrente experiencia de muchas viudas prestigiosas castellanas. Dentro de este recorrido se pretende reconocer las articulaciones entre la condición de origen, los intereses de su parentela y las nuevas relaciones políticas y económicas que la mujer contrae; de modo de aportar elementos para una caracterización del perfil sociológico de las oligarquías cuyos destinos, como podrá observarse son diversos.

\section{UNA RESEÑA GENERAL DE LOS GRANDES PROPIETARIOS ABULENSES EN EL SIGLO XV}

Las oligarquías concejiles y las distintas ramas de la baja nobleza local, integradas tanto en los órganos de gobierno concejil, como en los aparatos de poder monárquico, han sido extensamente estudiadas por diferentes autores para distintas regiones de la península ${ }^{16}$. En muchos casos se ha definido sin rodeos a estos grupos

régimen municipal”, MONSALVO ANTÓN, J. M., "Parentesco y sistema concejil. Observaciones sobre la funcionalidad política de los linajes urbanos en Castilla y León (Siglos XIII-XV)“, Hispania, LIII/3, 185, 1993, pp. 937-969, esp. 943. Estas cuestiones las hemos abordado en LUCHÍA, C., "Tierra, poder y violencia en torno a la consolidación de las oligarquías concejiles en el siglo xV: El caso de los caballeros abulenses", Espacio, Tiempo, Forma, III (Historia Medieval),(en prensa)

${ }^{15}$ Véase el interesante trabajo de GIULIODORI, S., “¿Qué fuentes? ¿Qué cuestiones? Los estudios sobre la capacidad patrimonial de la mujer en Italia durante la Baja Edad Media", Studia Historica (Medieval), 26, 2008, pp. 91-109; GROPPI, A., (Ed), Clio. Histoire, Femmes et Société, Femmes, dots et patrimoines, vol. 7, 1998; BECEIRO PITA, I., "La mujer noble en la baja Edad Media castellana", La condición de la mujer en la Edad Media: Actas del Coloquio celebrado en la Casa de Velázquez, (1984), 1986, pp. 289-314.

16 "La sociedad de las ciudades y villas era, en la segunda mitad del siglo XV, de una gran variedad. En la cumbre se hallaba, obviamente, el sector dominante, denominado por la historiografía con la expresión de «oligarquía urbana». Estamos hablando de los que controlaban la urbe desde el punto de vista 
como parte del estamento nobiliario. Sin embargo, la identificación entre esto: grandes y poderosos propietarios y la nobleza merece algunas precisiones que di ferencien las cualidades constitutivas de ambos grupos ${ }^{17}$.

La disposición de grandes extensiones de tierras, por cesión regia o mera usur. pación, no importa de por sí la adquisición del estatuto de nobleza. Por el contrario sí son centrales el disfrute de poderes señoriales sobre tierras y vasallos, la capa cidad de extraer el plustrabajo campesino, la patrimonialización de las jurisdiccio nes obtenidas, el ejercicio privado de la justicia. Estos son elementos sustantivo:

político, pero al mismo tiempo solían ser las familias de mayor poder económico y, en definitiva, de u1 gran prestigio social”, VALDEÓN, J., "Isabel la Católica y la sociedad de Castilla y León”, en versió1 digital: http://www.cervantesvirtual.com/servlet/SirveObras/01338331900804177645802/p0000001.htm\#I_0_ ÍDEM, “Las oligarquías urbanas”, en Ladero Quesada, M. A.; Álvarez Palenzuela, V.; Valdeón Baruque J., (Coords), Estudios de Historia Medieval. Homenaje a Luis Suárez, 1991, pp.509-522

Véase también entre otros, DIAGO HERNANDO, M., "Estructuras familiares de la nobleza urban: en la Castilla bajomedieval: los doce linajes de Soria", Studia Historica (Medieval), 1992, pp. 47-71 SÁNCHEZ BENITO, J. M., "Estructura social de un pueblo de Castilla en época de los Reyes Católicos Fuentes, aldea de Cuenca", En la España Medieval, vol. 31, 2008, pp. 97-122; MONSALVO ANTÓN J. M., "Gobierno municipal, poderes urbanos y toma de decisiones en los concejos castellanos bajome dievales (Consideraciones a partir de concejos salmantinos y abulenses", Las sociedades urbanas en lc España Medieval XXIX Semana de Estudios medievales, Estella, 15 a 19 de julio de 2002, 2003, pp 409-488; ÍDEM, "En torno a la cultura contractual de las elites urbanas: pactos y compromisos político (linajes y bandos de Salamanca, Ciudad Rodrigo y Alba de Tormes", Foronda, F.; Carrasco Manchado A. I., (Coords), El contrato político en la Corona de Castilla. Cultura y sociedad políticas en los siglos X. $y$ XVI, Dykinson, 2008, pp. 159-209; del VAL VALDIVIESO, I., “Aspiraciones y actitudes sociopolíticas una aproximación a la sociedad urbana de la Castilla Bajomedieval”, en Bonachía Hernando, J. (Coord) La ciudad medieval: aspectos de la vida urbana en la Castilla Bajomedieval, Univ. de Valladolid, 1996 pp. 213-254.

${ }^{17}$ Son diversas las caracterizaciones sociológicas de este grupo, desde la temprana visión de Rafae Gibert para quien el privilegio de exención tributaria así como el control del aparato político local asimili a los caballeros al patriciado urbano, GIBERT, R., "Estudio histórico jurídico" en Sáez, E., Los Fuero. de Sepúlveda, Segovia, 1953. Por su parte, otros asimilan a los caballeros urbanos como parte de la clası feudal, MÍNGUEZ FERNÁNDEZ, J. M., "Feudalismo y concejos. Aproximación metodológica al aná lisis de las relaciones sociales en los concejos medievales castellano-leoneses", En la España Medieval 3, 1982, pp. 109-122; MORENO NÚÑEZ, J. I., "Los Dávila...”, 1982; SANTAMARÍA LANCHO, M. "Del concejo y su término a la comunidad de ciudad y tierra: surgimiento y transformación del señorí urbano de Segovia (siglos XIII-XIV)", Studia Historica (medieval), 3, 1985, pp. 83-116; BARRIOS GAR CÍA, A., Estructuras agrarias y de poder en Castilla. El ejemplo de Ávila (1085-1320), Salamanca, 1983 MONSALVO ANTÓN, J. M., El sistema político concejil. El ejemplo del señorío medieval de Alba d. Tormes y su concejo de villa y tierra, Salamanca, 1988; BONACHÍA HERNANDO, J. A., "El concej، como señorío (Castilla siglos XIII-XV)", Concejos y ciudades en la edad Media hispánica, Móstoles, 1990 pp. 429-464; DIAGO HERNANDO, M., "Caballeros e hidalgos en la Extremadura castellana medieva (siglos XII-XV)", En la España medieval, 15, 1992, pp. 31-62. Reyna Pastor propone, desde una pers pectiva materialista, que estos grandes propietarios de tierras y ganado conforman una "aristocracia cam pesina", como variante conservadora del campesino rico inglés, PASTOR, R, "En los comienzos de un: economía deformada: Castilla”, Desarrollo Económico, vol. 9, 36, 1970. Carlos Astarita identifica a lo caballeros como productores simples de mercancías, pero precisando que esta clase de campesinos in dependientes tiene "una funcionalidad en la reproducción feudal a partir del poder que, como colectivo ejercieron sobre las aldeas", ASTARITA, C., op. cit., 2005, p. 33. 
que deben ser tenidos en cuenta para situar a las elites dentro de la condición señorial ${ }^{18}$. De este modo, el estatus característico de la clase feudal es la propiedad privada de un derecho de mando territorial por parte de un linaje, que no se confunde con el concepto más general e impreciso de "ennoblecimiento", que denota la adopción de pautas culturales de la nobleza por parte de la elite de los plebeyos o del "tercer estado".

En el análisis de los linajes abulenses encontramos numerosos propietarios que actúan, dentro de una política familiar durante los siglos desde la instalación en el área ${ }^{19}$, como hombres fuertes, cuyo poder discrecional se ejerce, se exhibe y se manifiesta sin que por ello estemos necesariamente frente a verdaderos señores loca${ }^{l e s}{ }^{20}$. La oligarquía abulense, como la de otras ciudades importantes del reino ${ }^{21}$, se encuentra fuertemente estratificada, entre un grupo de propietarios importantes urbanos que pugnan por ocupar algunos cargos dentro del municipio, otros cuyas fuentes de poder económico se vinculan a la participación en actividades lucrativas

${ }^{18} \mathrm{La}$ generalización de las usurpaciones de términos en todas las áreas de realengo, con la consiguiente amenaza para los intereses tanto políticos como fiscales de la Corona, lleva entre muchas otras acciones, como las dictadas en las Cortes de Toledo de 1480, a una intervención directa de los soberanos. En estas Cortes los soberanos reconocen: "somos informados que muchas çibdades e villas e logares de nuestros rreynos, especialmente de nuestra corona real, estan muy desapropiados e despojados delos dichos sus lugares e jurisdiçiones e terminos e prados e pastos e abrevaderos", Cortes de las Antiguos Reinos de León y Castilla, Real Academia de la Historia, Madrid, T. IV, 1882, Pet. 82, p. 155. (Cortes)

Así se observa también en la "Comisión sobre términos a Pedimiento" en la que los reyes encomiendan a Juan Chacón, adelantado mayor del reino de Murcia, a que delimite nuevamente los términos cuyos mojones hayan sido perturbados por los usurpadores: "llamadas e oydas las partes, ynformeys por qué partes e límites están puestos los dichos mojones de antiguo tienpo a esta parte (...) e donde fallardes los dichos mojones e por amas partes fueren reconosçidos los renovedes e señaledes de nuevo, do estovieren caýdos los renovedes e tornedes a reedificar seyendo conformes las dichas partes deslindando a amojonando (...) atento al thenor e forma de la ley por nos fecha en las Cortes de Toledo lo veais e determinéis cerca de ello todo lo que fallardes por derecho por vuestra sentencia o sentencias interlocutorias como definitivas", Archivo general de Simancas, RGS, 149 103, 94.

${ }^{19}$ En un pleito por usurpación de tierras concejiles, uno de los caballeros da cuenta de ello: "Sancho Sánchez (...) tenía e poseýa unos echos que son cerca de Peñalbueytre, los quales quedaron de su visavuelo et de su abuelo e de su padre, et después quel dicho padre fincó quel que los posee según que los poseyeron sus anteçesores”, Doc 75, 21 de enero de 1414- 22 de octubre de 1415, LUIS LÓPEZ, C.; DEL SER QUIJANO G., Documentación Medieval del Asocio de la Extinguida Universidad y Tierra de Ávila, II Tomos, Ávila, 1990-92, T. I, p. 292. (Asocio)

${ }^{20}$ Este aspecto ha sido trabajado en nuestra tesis doctoral La dinámica de la propiedad comunal y las condiciones de desarrollo transicional del feudalismo al capitalismo en el área concejil de realengo castellana (siglos XIV-XVI), (2009) Inédita.

${ }^{21}$ Aunque no compartimos el rígido corte que establece Diago Hernando entre la caballería villana originaria de los siglos repobladores y la que aparece dominando las ciudades en los últimos siglos medievales, destacamos la centralidad que otorga a los cambios que se producen dentro de las elites urbanas a partir del reinado de Alfonso XI y que luego se asentarán durante el de los soberanos católicos. La concesión de privilegios y la inclusión dentro los órganos de gobierno local, así como la integración en la estructura administrativa superior del reino, ameritan un estudio comparativo de las diferentes trayectorias de este sector privilegiado entre las diferentes ciudades de la Extremadura. DIAGO HERNANDO, M., op. cit., 1992, "Caballeros e hidalgos..., p. 52 y ss. 
como el comercio ${ }^{22}$ y el arrendamiento de oficios reales ${ }^{23}$, como el cobro de distintas tasas e impuestos, junto a un grupo técnico profesional de notarios, escribanos y contadores ${ }^{24}$, y por último, aquéllos cuya solidez deviene de su condición de grandes propietarios de tierras y ganado que adquieren progresivamente poderes jurisdiccionales, de hecho o de derecho, sobre sus territorios ${ }^{25}$. Este último grupo no elude la apelación a otras vías de ascenso económico, que en general se combinan con su principal orientación de propietarios pecuarios ${ }^{26}$, a través de las cuales acrecientan sus fortunas y construyen vínculos con otros sectores dentro y fuera de Ávila ${ }^{27}$. Este elite, dentro de la elite, es precisamente en la cual situamos a los Dávila, cuyos orígenes y arraigo en la ciudad y su tierra se remontan a los tempranos siglos repobladores, de donde deriva entre otros atributos, su gran prestigio social en el área. La mayoría de los integrantes del linaje participan tanto de la obtención de bienes comercializables, como la lana, así como de la extracción de excedente campesino, por medio de concesiones regias, o por la mera usurpación de ellas.

En este punto nos interesa destacar el dinamismo y la capacidad de elaborar diversas estrategias para consolidar y aumentar su poder tanto patrimonial como político ${ }^{28}$.

${ }^{22}$ Sobre la importancia de las actividades mercantiles de las elites urbanas, véase entre otros, OLMOS HERGUEDAS, E., "El poder urbano y sus estrategias para influir sobre el territorio: aproximación metodológica desde las ordenanzas concejiles castellanas", Arizaga Bolumburu, B.; Solórzano Telechea, J. A., (Coords), La ciudad medieval y su influencia territorial, Instituto de Estudios riojanos, 2007, pp. 493-519; COLOMBO, O., "Crecimiento mercantil y regulación política (Castilla siglos XIV-XV)", Studia Historica (Medieval), 26, 2008, pp. 153-175.

${ }^{23}$ Acerca de la patrimonialización de los oficios reales en el panorama político del siglo XV castellano, ORTEGA CERVIGÓN, J. I., "Prestigio político y oficios reales: la nobleza conquense bajomedieval en el entorno cortesano", Anuario de estudios Medievales, 37/2, 2007, pp. 563-595.

${ }^{24}$ Para el caso de Burgos Casado Alonso señala la importancia de una oligarquía urbana mercantil que invierte en tierras en el entorno rural pero cuya base originaria de riqueza es el comercio, el arrendamiento de rentas reales, municipales, eclesiásticas, las artesanías y el control de la banca y el cambio, CASADO ALONSO, H, "La propiedad rural de la oligarquía burgalesa en el siglo XV", En la España Medieval, 6, 1985, pp. 581-596, esp. 584. Como señala Jara Fuente "la historiografía se muestra concorde al entender estos procesos de gestión de la fiscalidad urbana como mecanismos de integración de aquellos personajes, los arrendatarios de las rentas concejiles en el esquema del poder en los municipios y, así mismo, de integración social e incorporación a las élites; un hecho, éste, que vendría facilitado por la proximidad y participación en el marco del poder urbano", JARA FUENTE, J. A., "Elites y grupos financieros en las ciudades castellanas de la Baja Edad Media”, En la España Medieval, 27, 2004, pp. 105-130, esp. 109

${ }^{25}$ Respecto de la evolución de los grupos dominantes urbanos en el siglo XV, señala Isabel del Val Valdivieso: "Al trasponer el umbral del siglo XV existe una oligarquía claramente afianzada en las ciudades. Si en un primer momento esta clase estuvo constituida, principalmente, por caballeros villanos e hidalgos, se vio obligada después a abrir sus filas a nuevos integrantes, procedentes del común del sector enriquecido a través de la actividad mercantil; éstos, aunque le transforman de alguna manera no le hacen cambiar ni sus características más clásicas, ni su tradicional modo de hacer", DEL VAL VALDIVIESO, M. I., op. cit., 1994, esp. 157.

26 "En el mundo feudal que nos ocupa, la tierra constituye un elemento imprescindible para asentar cualquier relación de poder", ídem., p. 158.

${ }^{27}$ Ibidem

${ }^{28}$ Esta idea de multiplicidad y diversidad de estrategias que hallamos en los grupos privilegiados urbanos, la plantea de modo convincente para el estudio de las elites campesinas, FURIÓ, A., "Las elites 
Afirma Pascua Echegaray: "la oligarquía de las ciudades castellano-leonesas tenía como principal medio de fortuna la tierra, el ganado, los señoríos jurisdiccionales y la participación en las rentas de la monarquía, siendo comercio y artesanía dos actividades secundarias" ${ }_{29}$.

\section{MARÍA DE ÁVILA: HIJA, ESPOSA, VIUDA: GRAN PROPIETARIA}

Si bien la activa participación de María de Ávila se destaca en la documentación desde las últimas décadas del siglo XV, no existen trabajos específicos sobre este particular personaje, a excepción de una contribución de origen monástico, cuya información se orienta más a caracterizar la vida religiosa del agitado siglo $\mathrm{XV}$, que a precisar las cualidades sociológicas de doña María y su linaje ${ }^{30}$.

María de Ávila pertenece al originario linaje abulense de Esteban Domingo, descendiente de los serranos, aquél grupo originario que participara activamente en las guerras defensivas en tiempos del asentamiento de la población sobre el territorio $^{31}$. Hija de Gil de Ávila y de Inés de Zavarcos, tal como menciona en su testamento ${ }^{32}$, gracias al favor que recibe de la Reina Católica, logra integrarse a la nobleza de nuevo cuño que se está consolidando en Castilla por medio de dos ventajosos matrimonios ${ }^{33}$. Como señala Giuliodori, "la producción testamentaria puede revelar una gran cantidad de características sobre las estructuras familiares, aunque éstas se observen a través del filtro de los formularios notariales y de la interpretación de las preferencias en la elección del destino de unas donaciones de carácter patrimonial" ${ }^{34}$.

Si recorremos brevemente la biografía de Doña María de Ávila, la primera mención sobre su vida activa es precisamente a partir de los logros del final de su existencia. En

rurales en la Europa Medieval y Moderna”, Rodríguez, A., (Ed.), El lugar del campesino. En torno a la obra de Reyna Pastor, PUV, Valencia, 2007, pp. 391-421.

${ }^{29}$ PASCUA ECHEGARAY, E, op. cit., 2007, p. 228.

${ }^{30}$ MONTESINOS GARCÍA, B., "María Dávila: La caridad de Santa María de Jesús", "La clausura femenina en España", Actas del Simposium: 1/42004, Campos y Fernández de Sevilla, F., (Coord), vol. 2, 2004, pp. 1271-1320. Aquí hallamos la transcripción completa del testamento de María de Ávila a partir del cual hemos podido corroborar muchos de los datos que sostienen este trabajo.

${ }^{31}$ GÓMEZ MORENO, E., "Crónica de la población de Ávila”, Boletín de la Real Academia de Historia, CXIII, 1943.

${ }^{32}$ Entre las mandas que deja en su testamento señala la obligación de que se celebren misas en memoria de sus padres: "mando, que en el dicho monesterio de Santa María de Jesús y el abadesa y monjas dél sean obligadas de haser decir en la iglesia del dicho monesterio de Santa María de Jesús, cada día perpetuamente, para sienpre jamá, quatro misas resada, la vna por las ánimas de Gil Dávila y de Doña inés de Zavarcos, mjs señores y padres”, MONTESINOS GARCÍA, M. B., op. cit., Anexo, p. 1308.

33 "los límites entre nobles tradicionales de sangre y elementos 'no nobles' de la clase dominante urbana se van borrando progresivamente a lo largo del siglo XV, como lo atestigua la actitud tomada por los caballeros villanos abulenses, que, en 1495, defienden su privilegio de exención frente a la pretensión pechera de incluirles en los padrones fiscales", DEL VAL VALDIVIESO, M. I., op. cit., 1994, pp. 157158. Véase MORENO NÚÑEZ, J. I., La tierra de Ávila en la Baja Edad Media (siglos XIII-XV), Tomo II, Madrid, 1990, pp. 439-441.

${ }^{34}$ GIULIODORI, S., op. cit., p. 99. 
1502, aparece como fundadora y dotadora del Monasterio de Las Gordillas, territorio que en sus orígenes pertenecía como villa a la Corona, bajo los Reyes Católicos, y que en 1478 es adquirida por medio de compra por Fernán Núñez de Arnalte, primer esposo de Doña María, quien muere en diciembre del siguiente año ${ }^{35}$.

En 1483 prosigue la estrategia tanto patrimonial como política de su primer marido; y contrae nuevas nupcias con el Capitán Don Fernando de Acuña, segundo hijo del Conde Pedro de Acuña, quien fuera señor de Buendía, de las Villas de Dueñas, Guarda Mayor de las mestas y cañadas de Castilla y Gran privado de los Reyes Católicos ${ }^{36}$. La nueva unión, sin dudas resulta sumamente beneficiosa para los intereses tanto económicos como políticos de María y su linaje. En 1484 por orden de los soberanos, Fernando de Acuña y su esposa son enviados como virreyes a Sicilia, donde el imperio hispánico pretendía consolidar sus posiciones. Una década estuvieron allí resolviendo asuntos de estado, hasta que en 1495 fallece el segundo esposo, dejando una situación financiera compleja, que incluye deudas debidas al ejercicio de su función; pero también importantes beneficios devenidos de la misma y de las operaciones privadas que realizara con propietarios del lugar. En este sentido, más allá de los problemas que la muerte de su marido conllevan, la situación patrimonial de María no deja de ser sólida, teniendo en cuenta las numerosas transacciones que había llevado a cabo a lo largo de su vida en su tierra de origen y en otros concejos, como el de Segovia, donde obtiene varias de sus numerosas heredades.

La vida de Doña María de Ávila se apaga lentamente; luego de ingresar al convento de Calabazanos en Palencia, por bula del papa Alejandro VI ${ }^{37}$ y autorización expresa del rey para que permanezca en él hasta que se culmine la edificación del monasterio de Las Gordillas en el que finalmente muere en el año $1511^{38}$.

Hasta aquí una somera descripción de los pasos más significativos de la intensa vida de esta viuda que en cierta forma describe la fortaleza y la posición adquirida por muchas de las mujeres pertenecientes a los linajes más poderosos de los sectores privilegiados castellanos.

Sobre la base de un reconcentrado estudio documental intentaremos identificar las diversas prácticas que emprende el linaje para acrecentar su poder en la región y extenderlo fuera de las fronteras del concejo abulense. Desde esta perspectiva es que se hará el seguimiento de las acciones de María de Ávila, sus parientes, servidores, criados y mayordomos.

\footnotetext{
35 "es nuestra merçed e voluntad de vender (...) la nuestra casa e heredamiento de Las Gordillas, con todas sus tierras e términos anexos e acrecentamientos e montes e valles e prados e pastos e ríos e arroyos e pasadas de molinos e riberas e sotos e aguas manantes e corrientes, e estantes, e el señorío de todo ello con todo su distrito e termino e inpediçión e juridiçion alta e baxa, e mero mixto Ynperio (....) a vos Fernand Núñez Arnalte, nuestro tesorero e secretario, para que todo lo ayades e tengades por vuestro propio, por juro de heredat, para siempre jamás, para vos e para vuestros herederos", Doc 113, 1478, abril, 18. Madrid, DMMLG, Vol. II, p. 11.

${ }^{36}$ Véase ACUÑA RUBIO, C., "Parentescos de Don Fernando de Acuña: Capitán General y Justicia Mayor en el reino de Galicia, Virrey, Lugarteniente de su Majestad en el reino de Sicilia", Estudios de genealogía, Heráldica, y nobiliaria de Galicia, 6, 2007, pp. 13-46.

${ }^{37}$ Véase Doc 381, 7 de septiembre de 1495, Roma, pp. 175-176, DMMLG, Vol. IV

${ }^{38}$ Véase Doc 398, 8 de febrero de 1497, Tortosa, pp. 210-211, DMMLG, Vol. IV
} 


\section{LINAJE, PATRIMONIO Y VÍNCULOS POLÍTICOS}

En la región abulense existe un grupo reducido de familias que concentran en sus manos las tierras más importantes en cuanto a los recursos que éstas proveen. En particular, amplias superficies de pasturas para abastecer las vastas cabañas ganaderas de las que los principales hombres de Ávila son propietarios. Sin embargo, los sectores privilegiados de la villa no sólo disponen de espacios rurales, sino que acrecientan su control sobre bienes estrictamente urbanos, así como de actividades vinculadas al comercio, el arrendamiento de tasas, entre otros negocios sumamente lucrativos ${ }^{39}$. De este modo, la diversificación de las estrategias económicas de los linajes les permite reforzar su posición no sólo en la ciudad y su tierra sino también ampliarla a las regiones cercanas ${ }^{40}$.

Si bien la participación plena de María de Ávila, aparece ya siendo mayor y producto de su primer matrimonio con Fernando Núñez de Arnalte, vecino de la ciudad de Ávila, y tesorero de los Reyes Católicos, la parentela a la que pertenece venía realizando una serie de actuaciones tendientes a fortalecer su situación patrimonial. Remitiéndonos estrictamente al fondo documental que sostiene esta colaboración, las primeras menciones que involucran a la familia directa de María aparecen a mediados del siglo XV. Se trata de una serie de ventas que su madre, Inés de Zavarcos, realiza como tutora de María. Inés se desprende de bienes de poco valor a lo largo de 1459: unas casas pajizas, un corral, unos huertos etc. ${ }^{41}$. Sin embargo, unos años más tarde, la madre de María aparece adquiriendo por medio de compras y trueques, importantes tierras dentro del término abulense, las superficies y el valor que por ellas se paga dan cuenta de la importancia del patrimonio que se está consolidando y concentrando en la región. Desde 1464 hasta 1477 son varias las transacciones con vecinos de la ciudad, por medio de las cuales la viuda de Gil de Ávila asume una presencia importante como propietaria en la Tierra. La adquisición en 1468 por parte de Inés de Zavarcos de una yugada de heredad y partes de otras en Mediana de Boltoya, Rebilla y Pedro Abad, por valor de 92000 maravedís, dan cuenta de la gravitación del linaje en el activo intercambio de tierras que se produce en Ávila ${ }^{42}$. En esta ocasión no sólo es destacable la entidad de la operación que se realiza sino la condición de quien traspasa los suelos: se trata de otro propietario importante: Álvaro del Águila, hijo de Juan Dávila y también vecino de la villa.

Atento al tipo de acciones que se emprenden respecto del control de los suelos, el cambio entre Blasco Suárez y su mujer, Beatriz González e Inés de Zavarcos, de la heredad que los primeros poseían en Herites, por unas yugadas de heredad en

\footnotetext{
${ }^{39} \mathrm{Al}$ respecto señala Pascua Echegaray la diversidad de fuentes de riqueza que forjan las oligarquías y que trascienden la propiedad de extensas cabañas ganaderas, PASCUA ECHEGARARY, E., op. cit., 2007,228 y ss.

${ }^{40}$ En la vasta documentación que provee el Asocio de Ávila y la recopilada en el Registro General del Sello, se reiteran los conflictos por tierras y límites entre Ávila y las villas de Sepúlveda, Segovia y Palencia; VVAA, Documentación medieval abulense en el Registro General del Sello, vol.VI- XVII, Ed. Gran Duque de Alba, Ávila, 1996-2004. (RGS)

${ }^{41}$ Véase Doc 40 a 44, DMMLG, Vol. I.

${ }^{42}$ Véase Doc 68, DMMLG, Vol. I
} 
Castilblanco y Encinas en poder de la viuda de Gil de Ávila ${ }^{43}$, señalan no sólo la política de acrecentamiento patrimonial sino también una tendencia a reordenar las propiedades y concentrar aquellas de mayor valor en torno a los núcleos más productivos de la Tierra. En este sentido, destacamos el dinamismo de los diferentes grupos de la oligarquía abulense en cuanto a la construcción de su poder territorial; práctica habitual también entre los señores ${ }^{44}$.

\section{MARÍA DE ÁVILA: MATRIMONIO, PATRIMONIO, PODER}

El matrimonio con Don Fernando Núñez de Arnalte, con estrechos vínculos con la Corona, estimula aún más la base patrimonial que recibe María de su propia familia ${ }^{45}$.

Las múltiples acciones por medio de las cuales la parentela de Doña María y su marido van adquiriendo suelos en diferentes zonas del área son variadas. Se exhibe documentalmente la mayor incidencia de las compras de tierras, de diferentes valor y extensión. Lo interesante de este tipo de prácticas es que no se limitan a la obtención de parcelas dentro del término abulense, sino que las mismas tienen singular incidencia en el territorio perteneciente a la villa segoviana. A diferencia de las compras y otras transacciones que constituyen la dote de María, la mayoría de las cuales se reducen al término abulense, su primer esposo tendrá especial interés en ubicarse como propietario en el término de Segovia; de allí las numerosas operaciones de compra venta que realiza en dos aldeas segovianas: Maello y Labajos.

Por otro lado, es de relevancia el carácter de los vendedores. Si bien existe una amplia presencia de labradores pobres que acuciados por las deudas y seguramente sometidos a las presiones de los poderosos, entregan a relativamente bajos precios pequeños suelos, también se observan transacciones con otros miembros de de los poderosos linajes locales. Las numerosas operaciones que este hombre de confianza de la reina realiza en las tierras de Segovia, con especial interés en la aldea de Maello, contrastan con el escaso interés demostrado por adquirir partes del término abulense.

La primera mención a este tipo de actuaciones del tesorero de los reyes la hallamos en 1469, cuando compra por 600 mrs. tres obradas de tierras en Maello, a un tal Sancho Martín, vecino de la aldea de Labajos ${ }^{46}$. La mayor intensidad de las

${ }^{43}$ Véase Doc 63 y 65, del 31 de diciembre de 1466, en DMMLG, Vol. I.

${ }^{44}$ Similitudes hallamos en el caso navarro, estudiado por Diago Hernando, quien advierte en La Rioja que dentro de los principales linajes, en particular el de Estúñiga, hay una suerte de distribución de incumbencias, al punto que se verifica que aquélla rama del linaje que obtiene señoríos y amplía su poder territorial en otras regiones no "fue la que intervino de forma activa en la vida política" del concejo. Para el caso que estudiamos pareciera que los Dávila presentes en la mayoría de las decisiones del órgano de gobierno local mantienen una relativa distancia con las actuaciones de la heredera protegida de los Reyes Católicos, véase DIAGO HERNANDO, M., "Linajes navarros en la vida política de La Rioja Bajomedieval. El ejemplo de los Estúñiga", Príncipe de Viana, Año 53, 197, 1992, pp. 563- 582, esp. 568

${ }^{45}$ Véase BECEIRO PITA, I., "Parentesco y alianzas políticas en Castilla (siglo XV)", Foronda, F.; Carrasco Manchado, A. I., Du contrat politique cultures et sociétés politiques dans la Peninsule Ibérique de la fin du Moyen Âge, Tooluse, 2007, pp. 9-28.

${ }^{46}$ Véase Doc 70, 28 de abril de 1469, DMMLG, Vol. I. 
compras se registra entre 1478 y 1479 , el año de su muerte, que suman un total registrado de 54 transacciones. Prioriza en sus adquisiciones, además de algunos inmuebles urbanos, las tierras de pan proveedoras directas de excedente campesino ${ }^{47}$, que va obteniendo por medio de pequeñas operaciones, aunque también se advierten prados y pastizales.

Veamos un ejemplo de ellas: Bartolomé Sánchez, vecino de Maello, vende por juro de heredad "dos obradas e media de tierras en el dicho logar Maello e sus términos, la una obrada frontera (...) con la parte que a las dichas tierras pertesnesçe de prados e pastos e montes e aguas e heras (...) por razón de seiscientos maravedís desta moneda" ${ }^{48}$.

Recordemos que Fernando Núñez ya dispone de la fortaleza de Las Gordillas ${ }^{49}$; desde esa posición territorial fortalecida por sus cargos en la administración regia, emprende una provechosa acumulación de suelos y de riquezas ${ }^{50}$. La operación de mayor relieve en cuanto a la cuantía involucrada y a los personajes que intervienen en ella la encontramos en 1479, cuando el Comendador de Villamayor, Francisco de Valderrábano, de la orden de Santiago, y su hijo, Fernando de Valderrábano, ambos vecinos de Arévalo ${ }^{51}$, venden al tesorero real "toda la heredad e bienes raýzes, ansý tierras de pan levar commo prados e pastos e casas e solares de casas e heras e fronteras e montes e exidos e aguas corrientes e estantes e manantes" en La-

47 “Juan Turreño, fijo de Martín López, vecino de Maello (...) vendo por juro de heredad para syenpre jamás a vos Ferrando Núñez, Tesorero e secretario del rey e reyna (...) vecino de la noble çibdad de Ávila, dos obradas de tierra de pan levar, que yo he e tengo en término del dicho lugar Maello que son al mojón de Lavajos", el precio de la operación se pacta en 330 mrs., Doc 119, 5 de junio de 1478, Ávila, DMMLG, Vol. II, p. 22.

${ }^{48}$ Doc 115, 1 de mayo de 1478. Ávila, DMMLG, Vol. II, p. 15.

${ }^{49}$ Como advirtiera tempranamente Quintanilla Raso, las fortalezas proliferan originariamente por acción de un grupo militar "en tránsito hacia la formación del grupo nobiliario", mientras que hacia la Baja Edad Media representan el centro simbólico de las atribuciones jurisdiccionales, QUINTANILLA RASO, M. C., "La tenencia de fortalezas en Castilla durante la baja Edad Media", En la España Medieval, 9, 1986, pp. 861-896, esp. 862.

${ }^{50} \mathrm{Al}$ morir Fernando Núñez, los Reyes Católicos reconocen no sólo los servicios prestados a su administración como tesorero y secretario real, sino los beneficios que obtuvieran de esos cargos: "E durante el tienpo de las dichas tesorerías (...) ovieron de recabdar e cobrar (...) por mandado de nos (...) grandes contías de maravedís e excelentes e doblas e castellanos e florines e enrriques e otros dineros reales e otras monedas de Aragón e Cecilia e del rey don Fernando de Nápoles, que los ovo e dar”, Doc 189, 8 de abril de 1480, Toledo, DMMLG, Vol. 2, p. 142.

${ }^{51}$ Para un estudio especifico sobre el proceso de señorialización de este concejo y en particular del comportamiento de los principales linajes que lo controlan, Ávila Seoane, N., "El proceso de señorialización del concejo de Arévalo en los siglos XIV y XV”, En la España Medieval, 26, 2003, pp. 97-126. En la Documentación del RGS, la villa de Arévalo aparece mencionada en varias ocasiones, dentro de este proceso de creciente patrimonialización por parte de los sectores privilegiados de las oligarquías urbanas y de las noblezas locales: "Sepades que por parte del conçejo (...) de la villa de Arébalo (...) diciendo que algunos conçejos e otras personas particulares asý de la dicha villa conmo de sus comarcas les tienen tomados e ocupados e entrados muchas dehesas e montes e prados e pastos e aguas e abrevaderos (...) e los guardan e defienden como sy fuesen suyos propios", DOC 5, 19 de enero de 1495, Madrid, RGS, Vol. XI, p. 16. 
vajos y Maello. "Con sus bueyes e aperos e dineros que de vosotros tengan resçebydos los renteros que de nosotros tienen arrendada fasta aquí la dicha heredad, e con la renta del pan deste presente año", por la suma de $158000 \mathrm{mrs}^{.2}$.

Las compras se suceden de manera incesante; en algunos casos con la actuación directa de Fernando Núñez, en otras, por poder delegado a sus mayordomos y alcaldes de la fortaleza de Las Gordillas. Hasta aquí María de Ávila no tiene ningún protagonismo en estas actuaciones. Su presencia aparecerá con fuerza a partir del testamento de su primer marido, que en su lecho de muerte la constituye como "legítima universal heredera" y le ordena " a la dicha María, mi muger, que dé e entregue al dicho prior toda mi fazienda" ${ }^{53}$. El prior al que hace alusión no es otro que Tomás de Torquemada, con quien había establecido estrechos vínculos y que a la muerte de Núñez de Arnalte se ve favorecido con la dotación del Monasterio de Santa Cruz de Segovia que dirigía ${ }^{54}$.

El encumbramiento de este caballero ascendido a miembro destacado de la nobleza local, por medio de sus vinculaciones con el poder monárquico, la adquisición de nuevos patrimonios y la alianza matrimonial con una descendiente del linaje de los Dávila revela el dinamismo interno de la oligarquía abulense. Afirman los Reyes Católicos que Fernando Núñez y su esposa "recabdaron e cobraron de muchos conçejos e caballeros e otras personas e iglesias e monesterios e universidades muchas quantías de maravedís e oro e plata e joyas e otras cosas" ${ }_{55}$. El cargo que asume el primer marido de María Dávila les permite posicionarse de una manera sumamente ventajosa respecto de otras ramas de los grupos privilegiados de Ávila y alcanzar un poder que excede el ámbito estricto de la ciudad y su Tierra ${ }^{56}$.

Tras la muerte del tesorero, los soberanos estrechan aún más el vínculo con la descendiente de los Dávila. En el mismo documento en que expresan su reconoci-

${ }_{52}$ Doc 141, 16 de febrero de 1479.Labajos, en DMMLG, Vol. II, p. 60.

${ }^{53}$ Doc 176, 26 de octubre de 1479, Toledo, en DMMLG, Vol. II, p. 117.

${ }^{54}$ El propio testamento de María Dávila brinda más elementos acerca de la postrimera voluntad de su primer esposo: "por quanto el testamento del dicho Hernand Núñez Arnalte, tesorero y secretario del rey y de la reyna nuestros señores, mi primero marido y señor, que santa gloria aya, yo prinipié el monesterio de Sasnto Thomás de Ávjla, y dí de los bienes del dicho tesorero (...) cuenco y medio en dineros para la edificación dél y cincuenta mill maravedís de juro y seiscientas hanegas de pan de renta para el mantenjmiento y provejmjento del dicho monesterio", citado en MONTESINOS GARCÍA, M. B., op. cit., Anexo, p. 1299.

${ }^{55}$ Doc 189,8 de abril de 1480, Toledo, DMMLG, Vol. II, p142.

${ }^{56}$ El estudio de Diago Hernando sobre la incidencia de la fiscalidad regia en el ámbito riojano revela la participación de este nuevo estrato nobiliario que se conforma a partir de la habilidad estratégica con que vinculan sus intereses con los del estado central: "Al analizar la cuestión de la incidencia de la fiscalidad de la monarquía sobre el territorio riojano durante el reinado de los Reyes Católicos desde la perspectiva de la percepción de las alcabalas, uno de los fenómenos que más llama nuestra atención es que la Real Hacienda no era la beneficiaria del producto de la recaudación de este impuesto en una parte importante de este territorio, sino que en su lugar eran varios miembros de la alta nobleza, con fuerte implantación como señores de vasallos en la región, los que se quedaban con dicho producto en un importante número de lugares.", DIAGO HERNANDO, M., "La incidencia de la fiscalidad de la monarquía en el territorio riojano durante el reinado de los Reyes Católicos. Notas sobre la recaudación de alcabalas", En la España Medieval, Vol. 30, pp. 173-215, esp. 178. 
miento por el desempeño de las funciones de su primer marido, los monarcas afirman: "vos la dicha María de Ávila dexastes e posistes en nuestras manos toda la dicha herencia e todos quantos bienes el dicho nuestro tesorero e vos avíades". La condición de mujer la pone bajo la "tutela" y protección de los reyes: "conmo soys muger e non soys docta nin enseñada en fazer nin dar la dichas cuentas (...) posiste en nuestras manos todos los dichos bienes e herencia del dicho Ferrando Núñez" " ${ }^{77}$. Sin embargo, pese a no ser "docta" no le faltó habilidad a María para proseguir una política de acumulación, ayudada por sus parientes, criados y mayordomos.

Al año siguiente del fallecimiento de su esposo, se observa a María emprendiendo una compra de tierras: "Antón Gonçález, escribano de nuestro señor el rey, vecino que só en Fituero (...) vendo a vos la señora doña María de Ávila, muger que fuiste del señor Ferrando Núñez (...) nueve obradas de tierras que yo he e tengo en Maello" s8. El valor de la operación es de $2250 \mathrm{mrs}$ y evidencia la continuidad de la estrategia de acrecentamiento patrimonial de su primer esposo. La viuda realiza en término abulense unas 11 compras y cuatro más cuando contrae nuevo enlace. Si bien las operaciones son escasas, el valor de los bienes en Ávila y su tierra es significativo. María invierte entre 1480 y 1484, en estas adquisiciones, entre las que se encuentra un molino ${ }^{59}$, unos $243800 \mathrm{mrs}$, a los que se sumarán los 17800 que pagará junto a su segundo esposo. Un total de $261600 \mathrm{mrs}$ destinados a afianzar su posición patrimonial en su tierra de origen y por ende en la de sus parientes.

Luego de las segundas nupcias concertadas por los reyes con Fernando de Acuña ${ }^{60}$, la proyección del poder económico se despliega cualitativamente. Segundogénito de un miembro de la nobleza menor castellana, recibe en herencia de su padre, por estar excluido del mayorazgo, una carta de donación entre vivos:

"dono traspaso e fago donación e traspasación entre vivos s vos don Fernando de acuña, mi fijo legítimo de las aceñas que yo tengo e poseo en la dicha villa de Dueñas, e de los pisones que están junto con ellas del monte de Fransilla e de las viñas e huertas e heredamientos yo he avido e tengo por títulos de conpras (...) de siete mil cabeças de ganado menor (...) e de diez mil maravedís de juro de heredad que yo he e tengo situados en el alboz de la villa de Llanes" ${ }^{61}$.

La fortuna del nuevo esposo no es despreciable, pero veremos cómo las actuaciones que despliega a lo largo de los años, acrecientan su posición tanto económica como política. Si bien las operaciones registradas en nuestra documentación por

${ }^{57}$ Doc 189, 8 de abril de 1480, Toledo, DMMLG, Vol. II, p. 145.

${ }^{58}$ Doc 197, 28 de julio de 1480, Villacastín, DMMLG, Vol. II, p. 183.

${ }^{59}$ El valor del molino en Pero Abad, adquirido a Juan Suárez, morador de Tolbaños, aldea de Ávila, es de 19000 mrs, Doc 272, 5 de noviembre de 1484, Ávila, DMMLG, Vol. III, p. 94.

${ }^{60}$ La primera mención que aparece en el cuerpo documental de Las Gordillas sobre la unión matrimonial entre Fernando de Acuña y María de Ávila, la hallamos en un documento de junio de 1485: "yo don Fernando de Acuña, del consejo del rey e reyna nuestros señores, digo que por quanto vos doña María de Ávila mi muger”, Doc 276, DMMLG, Vol III, pp. 143-144.

${ }^{61}$ Doc 186, 7 de marzo de 1480. Buendía, DMMLG, Vol. II, p. 137.

${ }^{62}$ Véase Doc 106, 118, 125, 127, 138, 151, 163, 169, 170, DMMLG, Vol. I. 
Fernando de Acuña son relativamente escasas y se concentran particularmente en el término segoviano, en especial en la aldea de Labajos, algunos datos revelan aspectos de la vinculación entre los sectores privilegiados y las redes clientelares de servidores que construyen a lo largo de sus carreras. Pedro Vaquero, vecino de la aldea segoviana de Maello, vende al primer marido de María de Ávila en nueve oportunidades distintos bienes de relativo valor ${ }^{62}$. Las ventas en sí mismas no indican ninguna excepcionalidad, algunas obradas de tierras, una casa tejada con corrales; pareciera ser un caso más de los aldeanos que deben desprenderse de algunos de sus bienes. Sin embargo, años más tarde, el mismo Pedro Vaquero aparece como mayordomo del segundo esposo de María, adquiriendo junto y en nombre de éste las posesiones que obtiene en los diferentes lugares de Segovia, de donde él proviene ${ }^{63}$. El ascenso de este personaje no sólo responde a una arraigada política de conformación de redes de clientelas de los sectores privilegiados locales, sino también a una estrategia de inserción de los grandes propietarios en los pequeños ámbitos rurales, a través de sus vecinos, con los cuales se ha establecido una alianza ${ }^{64}$. Vaquero pareciera asimilarse más a un miembro de esas elites rurales que desde la perspectiva de Chris Wickham conforman las clientelas de los grupos privilegiados urbanos, actuando como intermediarios entre la baja nobleza local y el campesinado tributario ${ }^{65}$.

En muchos casos, cuando se compran tierras de Ávila que están fuera del señorío, o bien tierras de Segovia, los nuevos suelos no necesariamente se hallan incluidos dentro del originario derecho señorial, porque la existencia de un señorío privado supone el establecimiento de un derecho diferenciado. Si esas tierras seguían bajo la jurisdicción del rey, el linaje combinaba entonces tierras de señorío con otras en las que no ejercía derecho de jurisdicción, aun cuando podía lograrse la exención de rentas, por medio de privilegios regios. A modo de hipótesis proponemos que esas compras significarían un aumento del patrimonio, pero no la ampliación del señorío. En tanto, comparativamente, en los traspasos de tierras entre los nobles se menciona con detalles los bienes con todos sus usos y derechos respectivos; y se afirmaba taxativamente el traspaso del derecho de mando sobre

${ }^{63}$ Véase Doc 288, 289, 290, 291, 292, 293, 294, DMMLG, Vol. III.

${ }^{64}$ Sobre el tema véase JULAR PÉREZ-ALFARO, C., "La participación de un noble en el poder local a través de su clientela: un ejemplo concreto a fines del siglo XIV", Hispania. Revista de Historia, Vol. 56, 192, 1993, pp.137-171. (Dentro del número monográfico "Linajes nobiliarios, linajes urbanos y subpoblaciones monacales" (III Congreso de la Asociación de Demografía histórica, 1993). "Su procedencia social solía ser humilde, procedentes de otros linajes menores del mismo área geográfica o de las familias de las villas señoriales. Sus funciones eran principalmente domésticas y militares, especialmente escuderos y acostados; también podían realizar tareas administrativas — si eran letrados o secretarios bien preparados - y gubernativas en las villas. Recibían un numerario, aparte de los vestidos y los alimentos. Los criados tenían estrechos lazos personales y afectivos con los señores, ya que debían mostrar un alto grado de confianza y fidelidad; así alcanzaban una protección completa del señor, que a veces lograba su exención de pechos y tributos, la concesión de mercedes regias o cargos en los gobiernos locales o algunas dotaciones económicas", ORTEGA CERVIGÓN, J. I., "Lazos clientelares y bandos nobiliarios conquenses durante el siglo XV", Espacio, Tiempo y Forma, Serie III, Historia Medieval, T.19, 2007, pp. 211-231.

${ }^{65}$ WICKHAM, Ch., Community and Clientele in Twelfth-Century Tuscany. The Origins of the Rural Commune in the Plain of Lucca, New York, Clarendon Press, Oxford, 1998. 
los habitantes del territorio. Es decir que en la cesión constaba la transmisión del ban señorial.

\section{PODER DE ORIGEN, PODER DE ALIANZA}

El linaje de los Dávila se entrelaza con sectores de una nobleza de nuevo cuño, ligada a los aparatos de estado centrales que requieren de una vasta red de funcionarios, muchos de los cuales proceden de las oligarquías urbanas ${ }^{6}$. La construcción del estado que sostienen los Reyes Católicos proveerá de importantes oportunidades para que los sectores privilegiados de las villas ${ }^{67}$, que han acumulado poder en sus territorios; en muchos casos obteniendo mercedes reales, y en otros señorializando contra la voluntad de los soberanos sus espacios territoriales ${ }^{6}$. En este punto interesa reflexionar sobre la relaciones entre el linaje de origen de María de Ávila y el derrotero que sigue su vida luego de las dos uniones matrimoniales, por medio de las cuales encumbrará su poder bajo la celosa guarda de los soberanos.

La continuidad de los lazos de María, pese a su cercanía con las altas esferas cortesanas y a sus estrechos vínculos con el poder monástico, con su parentela originaria puede reconocerse en la presencia de algunos parientes en las actuaciones de la viuda. Así queda reflejado en la documentación abulense:

"teniendo sus antesçesores del dicho Pedro de Ávila casas, dehesas, prados e heredades diz que adquiriendo las otras casas, tierras e heredades (...) quedó e fincó por los antesçesores del dicho Pedro de Ávila, e fueron verdaderos señores e poseedores de todas las casas e heredades e pastos e dehesas" ${ }^{69}$.

La compra de tierras es parte de una política generalizada de los grupos dominantes de la villa, que pretenden en algunos casos alcanzar la condición de únicos propietarios en la zona y poder transformar sus posesiones en término redondo ${ }^{70}$, o bien en otros, apartarse del realengo y privatizar el espacio bajo su dominio.

${ }^{66}$ MENÉNDEZ PIDAL, F. "El linaje desplaza al individuo como sujeto de la calidad de nobleza: a la posesión de esa calidad se llegará a través del linaje; la obtendrá cada uno no aisladamente, sino como perteneciente a un linaje noble", El linaje y sus signos de identidad. En la España Medieval, extra 1, 2006, pp. 11-28, esp. 11.

67 "Desde esta época se manifiesta una correspondencia entre los privilegios de los caballeros y su posicionamiento como parte del poder de la monarquía", ASTARITA, C., op. cit., 2005, p. 95.

${ }^{68}$ Así aparece formulado en los numerosos litigios que emprenden los pecheros contra las oligarquías locales durante el generalizado proceso de privatización/señorialización que atraviesa todo el siglo XV: "sy esto oviese de pasar quel rrey e la rreyna, nuestros señores, rresçeberían mucho deservicio et la dicha çibdad e sus pueblos rresçebirían mucho dapño en sus pecherías, porque los dichos vezinos (....) se yrían a bevir e morar a los lugares de señoríos que son çercanos", Doc 186, 15 de octubre de 1490. Ávila, Asocio, T. II, p. 750

${ }^{69}$ Doc 86, 9 de junio de 1491, Córdoba, RGS, Vol. II, p. 191

${ }_{70}$ Para un estudio de la condición de término redondo, MONSALVO ANTÓN, J. M., "Paisaje agrario, régimen de aprovechamientos y cambio de propiedad en una aldea de la tierra de Ávila durante el siglo XV. La creación del término redondo de Zapardiel de Serrezuela”, Cuadernos Abulenses, 17, Ávila, 1992, pp. 11-110. 
La heredera de Gil de Ávila no desatiende los asuntos familiares sino que participa activamente de ellos, acompañando las actuaciones de su madre, quien nuevamente en 1480 interviene en uno de los tantos traspasos de tierras. En este caso se trata de una operación realizada entre Inés de Zavarcos y su hija con uno de los hombres poderosos de la ciudad, Velasco Núñez Vela, regidor abulense. El asunto refiere a unos suelos en dos aldeas de Ávila, Mediana y Rebilla y la transacción se plantea en los siguientes términos:

"de la una parte los señores Vlasco Núñez, vecino e regidor desta çibdad de Ávila e Juan Vlázquez Vela Núñez, su fijo e doña Catalina [su hija] (...) e de la otra parte, las señoras Inés de Zavarcos e doña María su fija (...) sobre razón que es trabtado de vender o trocar todos los bienes raíces que los dichos Juan Vlázquez e doña Catalina e el señor Vlasco Núñez (...) han tenido e poseído e tienen e poseen e les pertenesçe en mediana e en Rebilla e en sus términos (...) para que la dichas señoras Inés de Zavarcos e doña María su fija ayan los dichos bienes y heredades por conpra e sobre el presçio e quantýa e valor que por ellas les deven dar" ${ }^{\prime \prime}$.

La modalidad por la que se produce el traspaso de las tierras no es clara, si bien se habla de venta y trueque pareciera que existen formas de compromiso por medio de las cuales se producen cesiones de tierras, y en algunos casos intercambios de la titularidad de los suelos, en función de la propia dinámica y del balance de fuerzas existente hacia el interior de los grupos privilegiados locales ${ }^{72}$. La política de concentración de heredades prosigue, y un mes más tarde al citado documento, Sancha Martínez, vecina de la aldea abulense de Mediana vende "a vos doña María de Ávila (...) dieze seys obradas de tierras de pan levar e un lynar e un solar de casas e toda la otra heredad e bienes raíces que yo he e tengo en el dicho lugar Mediana e su término segund en que lo over de Blasco Núñez, regidor de la dicha çibdad, en çierto troque que con él fize" "`. El valor de la operación de compraventa, detrás de la cual se trasluce otra modalidad de traspaso de tierras, es de $7000 \mathrm{mrs} .{ }^{74}$.

${ }^{71}$ Doc 201, 2 de octubre de 1480, Ávila, DMMLG, Vol. II, p. 195.

${ }^{72} \mathrm{Si}$ bien para el estudio de los intercambios de tierras exclusivamente entre campesinos, el trabajo de Laura da Graca aporta elementos de sumo interés al debate teórico respecto de las diversas modalidades de transmisión de los suelos. Afirma la autora que "se prefiere el concepto de intercambio de tierras, puesto que el análisis comprenderá transacciones comerciales y no comerciales (trueques, arreglos); con independencia de la validez de la categoría «mercado de tierras», y de la presencia de elementos extraeconómicos, veremos que el conjunto de operaciones responde en última instancia a la finalidad del beneficio.", DA GRACA, L., "Intercambio de tierras y otras prácticas agrarias en concejos castellanos (siglo XV)", Anales de la Universidad de Alicante. Historia Medieval, 14, 2003-2006, pp. 111-144, esp. 115.

${ }_{73}^{73}$ Doc 202, 2 de noviembre de 1480, Ávila, DMMLG, Vol. II, p. 200.

${ }^{74} \mathrm{La}$ multiplicidad de las formas que adquiere el traspaso de tierras se aprecia con claridad en el siguiente documento: "Yo Rodrigo Orejón, vecino de la noble çibdat de Ávila, digo que porque ove conprado en pubica almoneda toda la heredad e bienes raíces que os fijos e herederos de Alfonso Suárez de Aldehuela (...) avían e tenían (...) que fuese en Mediana e Ribilla y sus términos (...) cedo y dexo y renunçio y trespaso en vos el dicho Francisco Suárez toda la dicha heredad”, Doc 227, 30 de octubre de 1481, Ávila, DMMLG, Vol. II, p. 268. 
Al mismo tiempo que María Dávila coparticipa de la política de acrecentamiento patrimonial de sus esposos, mantiene el vínculo con su familia de origen y protagoniza activas operaciones con los miembros más destacados de las oligarquías abulenses ${ }^{75}$. María Dávila no sólo no se distancia de su propio linaje, sino que se entrelaza con sus parientes en las estrategias de acumulación tanto de tierras como de afianzamiento de sus posiciones dentro del ámbito concejil ${ }^{76}$. De este modo, es posible comprender el poder que cede a su primo materno, Diego de Zavarcos, para que tome en su nombre la casa y fortaleza de las Gordillas ${ }^{77}$.

Los vínculos con otros miembros de la elite abulense se advierten con claridad en la venta del poderoso caballero Pedro de Ávila. De amplia actuación sobre la Tierra en lo que refiere a la ocupación y apropiación de suelos colectivos, dentro de lo que configura una política de concentración y acumulación patrimonial de su linaje, este caballero que ha adquirido rango señorial como señor de Villafranca y las Navas y que controla el aparato político local ${ }^{78}$, procede a la venta a María de Ávila de "todas las heredades e bienes raíces (...) que yo he e tengo e poseo (...) ansý por conpra commo por herencia (...) en Mediana e en Rebilla, aldeas desta çibdad" ${ }^{79}$. La transacción está valuada en unos $80000 \mathrm{mrs}$. No se trata aquí de una compra más, sino de un reordenamiento de los bienes hacia el interior de una elite urbana, cuyos linajes más poderosos, que se ubican en diferentes posiciones de poder tanto económico como político jurisdiccional, se encuentran claramente jerarquizados. En este sentido, consideramos que la fuerte movilidad de las oligarquías urbanas de Ávila, dentro de la que muchos de sus miembros alcanzan condición señorial integrándose a la nobleza local, expresa un permanente juego de desplazamientos y tensiones que permiten el ascenso y la consolidación de una

${ }^{75}$ Los intercambios de tierras con el regidor Vlasco Núñez continúan: "Yo Vlasco Núñez Vela, regidor, et yo Vela Núñez su fijo (...) vendemos por juro de heredad para syenpre jamás a vos la señora doña María de Ávila (...) toda la heredad e bienes raíces que nos los sobredichos avemos e tenemos (...) en Mediana e en Rebilla", la operación se concreta por un valor de 63000 mrs, Doc 208, 14 de abril de 1481, Ávila, DMMLG, Vol. II, p. 214.

${ }^{76}$ Podríamos seguir enumerando este tipo de actuaciones que involucran a miembros de su linaje originario y que a su vez dan cuenta de las complejas formas de transmisión de la propiedad entre los grupos de poder locales. Así advertimos la venta que Francisco Suárez, otro importante propietario abulense que aparece reiteradas veces en la documentación estudiada, realiza a María de Ávila: "quiero vender a vos la dicha señora doña Marýa (...) un portillo de heredad que el dicho Alfonso Suárez mi señor padre ovo conprado de Rodrigo del Águila mi tío". La operación no logra llegar a un acuerdo entre las partes respecto del precio de la misma, por lo que deben intervenir jueces árbitros quienes fijan el monto de la venta en 37000 mrs, Doc 223, 16 de octubre de 1481, Ávila, DMMLG, Vol. II, p. 242.

${ }^{77}$ Doc 216, 16 de mayo de 1481, Ávila, DMMLG, Vol. II, pp. 229-230.

${ }^{78}$ Así aparece en uno de los numerosos documentos que elevan las quejas de los pecheros de la Tierra abulense al Rey: "conmo Pedro de Ávila tiene ocupada la jurediçión de la dicha çibdad de Ávyla e su justiçia en logar del rey e de la reyna, nuestros señores (...) en perjuicio de la jurediçión real (...) ocupándoles la tierra e mandándoles e ponyéndoles miedos, e faziéndoles muchos temores e daños”, DOC 48, 17 de agosto de 1490, Córdoba, RGS, Vol. VII, p. 107.

${ }^{79}$ Doc 240, 20 de diciembre de 1481, Ávila, DMMLG, Vol. II, p. 296. 
"elite dentro de la elite" ${ }^{80}$, en distintas escalas dentro de la estructuración general del reino ${ }^{81}$.

Los linajes de la ciudad no limitan su influencia a la jurisdicción de la villa y su término, sino que por diferentes medios, logran vincularse a distintas instancias de la organización del estado monárquico, que bajo los Reyes Católicos se encuentra en proceso de fortalecimiento y expansión. La Corona necesita establecer apoyos, siempre complejos y ambivalentes, en las elites villanas, con las cuales mantiene una suerte de competencia y colaboración, en la medida en que si bien resultan un soporte central para la construcción del reino ${ }^{82}$; también constituyen una amenaza a la preeminencia del realengo en las villas y aldeas, sobre las que van extendiendo un poder cada vez más privado ${ }^{83}$. Así se aprecia en la discrecionalidad con la que actúa uno de los hombres poderosos de Ávila, Sancho Sánchez, sobre los campesinos tributarios. Declara un testigo:

"el dicho Sancho Sanchez faziendo carçel privada por su propia abtoridad le mandó prender, e dizen que le tenía preso en su fortaleza de la dicha Villanueva, faziéndose juez en su cabsa propia. E diz que le avía atormentado gravemente sin cabsa alguna. De lo qual diz que su fijo estava a punto de muerte". Ante lo cual la Corona ordena al juez enviado que: "[si] falláredes que el dicho Agustín está injustamente preso, le soltedes (...) sy (...) falláredes que ovo justa cabsa para le prender e el dicho Sancho Sánchez tiene preso, le saquedes del poder del dicho Sancho Sánchez (...) e ponedle en çarçel pública desa dicha çibdad de Ávila" ${ }^{84}$.

Sin embargo, la relación de María de Ávila y sus dos esposos, dista, al menos por lo que puede comprobarse a través de la documentación trabajada, de este nivel de enfrentamiento con el poder central. Por el contrario, la colaboración en las funciones asignadas por los soberanos le otorga a la casa enormes beneficios, y luego de la muerte de los dos cónyuges, la protección regia de la viuda, que culminará con

\footnotetext{
${ }^{80} \mathrm{Al}$ respecto señala Morsel: “el desmantelamiento y la recomposición de los patrimonios (...) se inscribían en una lógica más general de movilidad de los bienes y de las personas, destinada a asegurar a largo plazo la reproducción de los lazos sociales en el correspondiente grupo", Morsel, J. "Señores y villanos", La aristocracia medieval. El dominio social en Occidente (siglos X-XV), PUV, Valencia, 2008, pp. 205-265, esp. 213.

${ }^{81} \mathrm{Al}$ referirse a la situación de las ciudades castellanas en la Baja Edad Media indica que "muestran como rasgo común una clase dirigente considerablemente fracturada con intereses diversos y que desarrollaban estrategias políticas contradictorias", PASCUA ECHEGARAY, E., op. cit., 2007, p. 228. Para el caso de Ávila esas contradicciones no llegan al extremo de enfrentamientos de bandos como sí ocurriera en otras ciudades con fuerte presencia de aristocracia señorial.

82 "Al atender los rasgos principales de la fortuna de algunos de los miembros de las oligarquías urbanas del siglo XV (...) se constata que esta nobleza hallaba el fundamento de su poder en su relación con la monarquía y en la propiedad de la tierra”, PASCUA ECHEGARAY, E., op. cit., 2007, p. 229.

${ }^{83} \mathrm{El}$ fortalecimiento de los poderes privados en desmedro de los intereses monárquicos llega al extremo de la patrimonialización de los cargos, como es el caso del oidor real Pedro González de Ávila, que enviado para entender en cuestiones de usurpación de términos y jurisdicciones termina participando activamente de ellas, véase, Doc 102, Asocio, T. I, p. 438.

${ }^{84}$ Doc 10, 10 de febrero de 1496, RGS, Vol. XII, pp. 24-25.
} 
su entrega a la vida religiosa, con la consiguiente transmisión de parte de su importante patrimonio a manos eclesiásticas. En este sentido, algunas cuestiones merecen especial atención, en la medida en que parecieran diferenciar la actuación de María de Ávila de la de muchos otros miembros destacados de la elite abulense.

En primer lugar, el grado de colaboración que se advierte con la Corona, que difiere de las situaciones de tensión que advertimos en otros casos ${ }^{85}$. Por otro, la cercanía de María y su nueva parentela con las instituciones eclesiásticas a las que finalmente acude al final de sus días. Este último hecho no debiera llamarnos la atención, en tanto es habitual que las viudas que disponen de una importante fortuna sean objeto preciado para las instituciones monásticas que amplían así su base patrimonial. Pero en este caso, la documentación no revela siquiera desencuentros; sino que por el contrario la Corona favorece a la mujer y a sus esposos y el poder monacal se ve beneficiado por las constantes dotaciones y la herencia de la viuda, sin que exista oposición alguna a ello. Si bien en un nivel más extendido de la elite local, los conflictos con monasterios, conventos y abadías por el control de suelos y jurisdicciones suelen ser comunes; también reconocemos este doble juego que mencionábamos en relación al poder central: competencia y rivalidad, acorde a las circunstancias.

Así es como en la primera mitad del siglo XV entre los múltiples agravios que reciben los pecheros por la usurpación de sus suelos, advertimos en la voz de los procuradores aldeanos:

"que algunos cavalleros e escuderos (...) que diz que tenían e tienen entrados e tomados muchos de los dichos términos, prados, montes e dehesas e pinares a la dicha çibdat e sus pueblos han fecho e fizieron infiutosamente donaciones e traspasamientos de los dichos terminos, prados e montes e dehesas e pinares a algunas personas eclesiásticas, a fin e con entinçion de que non sean tenudos nin obligados a rresponder nin parecer ante vos sobrello" ${ }^{86}$.

Los caballeros mantienen una política de acumulación patrimonial que se remonta a los siglos anteriores al aquí estudiado; si bien es desde finales de la decimocuarta centuria y en especial en este agitado siglo XV, cuando la expansión territorial de las elites revela un importante despegue.

Si limitamos la indagación a la situación patrimonial de María de Ávila luego de sus dos matrimonios, podemos arribar a la conclusión del prioritario interés en asentar su posición en la tierra de Segovia, con las numerosas transacciones realizadas en aldeas de la ciudad, principalmente en Labajos y Maello; y una menor preocupación por el término abulense, en especial, las aldeas de Rebilla y

\footnotetext{
${ }^{85}$ En las peticiones que se elevan a las Cortes se advierte: "porque en estos regnos la mayor parte delos heredamientos está en poder de iglesias, monesterios, colegios o cofradías e hospitales, que mande en ello poner orden, mandando que no conpren mas bienes raíces de los que tienen, e si por herencia o donación (...) algunos bienes rayzes le fueren dados, que dentro de un anno los vendan", Cortes, Ordenamiento de las Cortes de Burgos de 1512 Pet. 18, p. 255.

${ }^{86}$ Doc 106, 19 de julio de 1434, Segovia, p. 443, Asocio, T. I.
} 
Mediana ${ }^{87}$. Hasta aquí, nada debiera sorprendernos, dado que ella, procedente de Ávila, dispone allí de una situación patrimonialmente afianzada. Sin embargo, la presencia en otras fuentes eruditas de caballeros de los linajes abulenses principales, muchos de cuyos miembros ocupan cargos de regidores en la ciudad, en pleitos por ocupación y adquisición de suelos fuera de la jurisdicción de Ávila merece profundizar la reflexión.

Curiosamente, otros caballeros villanos abulenses pretenden ocupar y apropiarse de suelos por diversas modalidades en las mismas aldeas segovianas en las cuales María consolida su dominio patrimonial. El caso más significativo es el denunciado por Juan González Mesón, en nombre de los lugares de Labajos y Maello. Sigamos su testimonio:

"los dichos conçejos tienen en uso e costumbre de mucho tiempo a esta parte de partir çiertos términos conçegiles para los labrar por pan (...) de poco tiempo acá , algunos cavalleros e escuderos e monesterios, ansý de la dicha çibdad de Segovia conmo de la dicha çibdad de Ávila, que tienen algunso heredamientos en los dichos términos (...) los perturban e non dexan hazer las dichas particiones nin labrar los dichos términos (...) nin gozar dellos e los corren e matan los bueyes (...) Lo qual diz que fazen por les poner en necesidad, porque los dichos labradores les vendan sus heredamientos" ${ }^{88}$.

Estamos aquí frente a una minoría de caballeros, cuyo prestigio, vinculaciones políticas, fortuna y poder en un sentido amplio, excede el límite de la ciudad a la que pertenecen y entrelazan sus intereses con otros provenientes de jurisdicciones cercanas; implantándose ellos mismos en los términos de otras ciudades. Esto demuestra el dinamismo de las elites villanas, las numerosas formas que encuentran para expandirse económica y políticamente y la necesidad de revisar la cuestión no desde una perspectiva rígidamente institucional, reducida a los intereses de un concejo, como si éste fuera una entidad monolítica, sino inscribiendo el problema dentro de la conformación del poder de los grupos privilegiados de las ciudades castellanas en la Baja Edad Media. Algunos grupos gozarán de su preeminencia y prestigio en el ámbito exclusivamente regional, otros formarán parte de una nobleza cortesana cada vez más nutrida.

Compras, traspasos, donaciones, usurpaciones, son algunas de las prácticas más destacadas. Sin embargo, pareciera que en el caso de María de Ávila, las actuaciones "por fuera de la ley" quedaron borradas de la documentación o efectivamente no fueron necesarias gracias a los vínculos políticos que sus alianzas matrimoniales, en particular con su segundo esposo, le permitieron establecer. ¿Esta diferencia en el tipo de conductas con respecto a otros miembros de los principales linajes de la ciudad es sólo producto de un vacío documental o bien responde a caracterizaciones sociológicas y proyecciones históricas divergentes de María y su linaje? Esta cuestión y algunos otros problemas derivados serán los que plantearemos a modo de hipótesis en las conclusiones de este trabajo.

\footnotetext{
${ }^{87}$ Véase anexo cuadro al final de este trabajo.

${ }^{88}$ Doc 22, 8 de marzo de 1493, Barcelona, RGS Vol. VIII, p. 87
} 


\section{REFLEXIONES FINALES PARA UNA AGENDA DE TRABAJO FUTURA}

Comenzamos esta contribución señalando que no trataría de una biografía de un personaje destacado de la vida castellana bajomedieval y advirtiendo sus límites y alcances. En este punto, luego del recorrido realizado podemos plantear algunas reflexiones que sirvan no sólo como conclusiones provisorias, sino que abran futuras líneas de trabajo.

María de Ávila, dos veces viuda, descendiente de uno de los linajes destacados abulenses es un personaje que sobresale del común de las mujeres de igual condición, pero que a la vez evoluciona acorde a los cambios que suceden en el medio histórico en el que vivió. En este sentido, podemos afirmar que expresa en sus múltiples actuaciones las transformaciones en el estado -luego del acceso al trono de los Reyes Católicos-, la capacidad de adaptación de los linajes urbanos al juego político y social de la época, y fundamentalmente, la diversidad de estrategias que las oligarquías de las principales ciudades castellanas elaboran para promocionarse, ascender o simplemente mantener sus posiciones de privilegio.

A través del personaje que reúne la abundante documentación que ha servido de base de este estudio es posible apreciar los lazos que unen de manera dinámica y cambiante, la vida política, social y económica de la ciudad con la del reino en su conjunto.

Hemos preferido emplear el concepto de "estrategias" de los linajes y de sus miembros, más que el de "programa" político o patrimonial de estos grupos político parentales, en tanto consideramos que las acciones que se van dando a lo largo del siglo XV, así como en las últimas décadas del anterior, si bien responden a un política familiar, tienen la cualidad de adaptarse creativamente a las circunstancias; de modo que los desarrollos de las distintas casas, así como de las diferentes ramas de las mismas conducen en el largo plazo a posiciones y condiciones divergentes. Esta última cuestión remite las últimas líneas de este trabajo a la pregunta esbozada más arriba en torno de la caracterización sociológica de los grupos privilegiados de las villas y su posición dentro y fuera de ellas.

La condición de grandes propietarios y detentadores de cargos en el aparato de gobierno municipal constituye a un grupo minoritario de privilegiados dentro de Ávila. Sin embargo, no todos estos sectores experimentarán el mismo desarrollo histórico. Algunos, como se ha mencionado ya, participarán activamente como productores simples de mercancías, lo cual les permitirá incorporarse dentro de una nueva lógica económica, si bien derivada del régimen feudal, aún subordinada a él y con potenciales posibilidades de despegue. En estos casos, el acceso al poder político, entendido como la ocupación de ventajosas posiciones institucionales, será un medio para ampliar sus expectativas económicas. Otros, por el contrario, encontrarán en la acumulación patrimonial, las exenciones fiscales, la obtención de mercedes regias y de funciones dentro de las instituciones monárquicas, una forma de autotransformación hacia una nueva nobleza que nutrirá al nuevo estado central en construcción. La adquisición de tierras en este caso, por la vía que sea, no será sólo un medio para alcanzar mayor potencia económica, sino una forma de afianzar una condición señorial que por origen les era inaccesible. En relación a la evolución de las elites rurales señala Joseph Morsel: "El hecho de que una parte de los grandes 
labradores hubieran podido con bastante regularidad (al igual que en la ciudad) introducirse en la aristocracia señorial (más tarde la nobleza) debe por tanto considerarse, más que el resultado de estrategias individuales de ascenso social, una consecuencia lógica del hecho de que ya eran partícipes del poder señorial”" ${ }^{9}$.

El linaje de los Dávila y en especial la figura de María a través de sus dos matrimonios, como señala Franco Silva en el exhaustivo estudio del patrimonio del Mariscal García González de Herrera ${ }^{90}$, no los convirtió en miembros plenos de la alta nobleza, aunque de alguna manera se encuentran emparentados con ella.

\section{ANEXO \\ ADQUISICIONES PATRIMONIALES DE MARÍA DÁVILA}

Compras de Fernando Núñez de Arnalte

\begin{tabular}{|c|c|c|}
\hline BIEN & LUGAR & PRECIO \\
\hline 3 obradas & Maello (Segovia) & $600 \mathrm{mrs}$ \\
\hline 50 obradas y una cuarta de era & Maello (Segovia) & Sin datos \\
\hline 9 obradas & Maello (Segovia) & Sin datos \\
\hline 22 obradas y media & Maello (Segovia) & Sin datos \\
\hline 10 obradas & Maello (Segovia) & $2500 \mathrm{mrs}$ \\
\hline 1 obradas & Maello (Segovia) & $2250 \mathrm{mrs}$ \\
\hline $\begin{array}{c}\text { 2 obradas de tierra y sus términos, prados, } \\
\text { pastos, aguas, montes, eras }\end{array}$ & Maello (Segovia) & Sin datos \\
\hline 2 obradas & Maello (Segovia) & $600 \mathrm{mrs}$ \\
\hline Un solar: media obrada & Maello (Segovia) & $635 \mathrm{mrs}$ \\
\hline 2 obradas y media de heredad & Maello (Segovia) & $530 \mathrm{mrs}$ \\
\hline 2 obradas de tierra de pan & Maello (Segovia) & $625 \mathrm{mrs}$ \\
\hline 4 obradas de tierras fronteras & Maello (Segovia) & $640 \mathrm{mrs}$ \\
\hline $\begin{array}{c}\text { Una casa tejada con sus corrales y 5 obra- } \\
\text { das de tierra de pan }\end{array}$ & Maello (Segovia) & $8515 \mathrm{mrs}$ \\
\hline $\begin{array}{c}5 \text { obradas de tierras foraño y 5 obradas } \\
\text { fronteras }\end{array}$ & Maello (Segovia) & $3100 \mathrm{mrs}$ \\
\hline $\begin{array}{c}\text { 6 obradas, 2 suertes un un solar camino a } \\
\text { Ávila, dos partes de una era y dos partes de } \\
\text { otra }\end{array}$ & Maello (Segovia) & $2220 \mathrm{mrs}$ \\
\hline $1 / 2$ casa tejada con su medio corral & Maello (Segovia) & $1720 \mathrm{mrs}$ \\
\hline 5 obradas de tierras de pan & Maello (Segovia) & $1300 \mathrm{mrs}$ \\
\hline 3 obradas de tierras de pan & Maello (Segovia) & $800 \mathrm{mrs}$ \\
\hline
\end{tabular}

${ }^{89}$ MORSEL, J., op. cit., 2008, p. 230.

${ }^{90}$ FRANCO SILVA, A., "La hacienda de un noble castellano a comienzos del siglo XV", En la España Medieval, T. V, 1986, pp. 361-380, esp. 380. 


\begin{tabular}{|c|c|c|}
\hline Un solar & Maello (Segovia) & $250 \mathrm{mrs}$ \\
\hline 4 obradas de tierras de pan & Maello (Segovia) & $2600 \mathrm{mrs}$ \\
\hline 5 obradas de tierras de pan & Maello (Segovia) & $1650 \mathrm{mrs}$ \\
\hline 1 tierra frontera de pan & Maello (Segovia) & $610 \mathrm{mrs}$ \\
\hline $1 / 2$ obrada de tierra frontera barbechada & Maello (Segovia) & $600 \mathrm{mrs}$ \\
\hline 1 obrada de foraño $y^{3} / 4$ de frontero & Maello (Segovia) & $390 \mathrm{mrs}$ \\
\hline 2 obradas de foraño & Maello (Segovia) & $510 \mathrm{mrs}$ \\
\hline Una obrada de frontero & Maello (Segovia) & $330 \mathrm{mrs}$ \\
\hline Un solar & Maello (Segovia) & $200 \mathrm{mrs}$ \\
\hline Obrada y $1 / 2$ de tierra foraña & Maello (Segovia) & $200 \mathrm{mrs}$ \\
\hline No especifica & Maello (Segovia) & $180 \mathrm{mrs}$ \\
\hline 5 obradas & Labajos (Segovia) & $2000 \mathrm{mrs}$ \\
\hline 1 casa con su corral y cerca & Labajos (Segovia) & $7000 \mathrm{mrs}$ \\
\hline 25 obradas de tierras de pan & Labajos (Segovia) & $15500 \mathrm{mrs}$ \\
\hline 2 tierras de heredad & $\begin{array}{c}\text { Labajos/Maello } \\
\text { (Segovia) }\end{array}$ & $2450 \mathrm{mrs}$ \\
\hline $\begin{array}{l}53 \text { obradas de tierras de pan, } \\
\text { con un solar frontero }\end{array}$ & Labajos (Segovia) & \multirow[t]{2}{*}{$50000 \mathrm{mrs}$} \\
\hline $1 / 2$ yugada de heredad de pan & Maello (Segovia) & \\
\hline 4 obradas & Labajos (Segovia) & $1500 \mathrm{mrs}$ \\
\hline 10 obradas de tierras de pan & Labajos (Segovia) & $5750 \mathrm{mrs}$ \\
\hline 16 obradas & Labajos (Segovia) & $6500 \mathrm{mrs}$ \\
\hline 5 obradas & Labajos (Segovia) & $2600 \mathrm{mrs}$ \\
\hline 3 obradas de tierras forañas & Labajos (Segovia) & $1000 \mathrm{mrs}$ \\
\hline 5 obradas de tierras de pan & Labajos (Segovia) & $2800 \mathrm{mrs}$ \\
\hline $\begin{array}{l}\text { Toda la heredad: tierras de pan, prados, } \\
\text { pastos, casas, eras, montes, exidos, aguas. } \\
\text { Con sus bueyes, aperos y rentas recibidas } \\
\text { de renteros }\end{array}$ & $\begin{array}{l}\text { Labajos/Maello } \\
\text { (Segovia) }\end{array}$ & $158000 \mathrm{mrs}$ \\
\hline 3 obradas forañas & Labajos (Segovia) & $1200 \mathrm{mrs}$ \\
\hline 10 obradas y $1 / 2$ cuarta & Labajos (Segovia) & $6200 \mathrm{mrs}$ \\
\hline 5 cuartas tierras forañas & Labajos (Segovia) & $400 \mathrm{mrs}$ \\
\hline 1 obrada y $1 / 2$ de tierra de pan & Labajos (Segovia) & $2500 \mathrm{mrs}$ \\
\hline 10 obradas de tierras de pan & Labajos (Segovia) & $5750 \mathrm{mrs}$ \\
\hline 15 obradas de tierras de pan & Labajos (Segovia) & $8580 \mathrm{mrs}$ \\
\hline
\end{tabular}




\begin{tabular}{|c|c|c|}
\hline 5 obradas de tierras forañas en 2 pedazos & Labajos (Segovia) & $1450 \mathrm{mrs}$ \\
\hline 11 obradas de tierras de pan & Labajos (Segovia) & $6000 \mathrm{mrs}$ \\
\hline 5 obradas & Labajos (Segovia) & $2775 \mathrm{mrs}$ \\
\hline 4 obradas de forañas & Labajos (Segovia) & $1400 \mathrm{mrs}$ \\
\hline 1 huebre y $1 / 2$ de tierra & Labajos (Segovia) & $540 \mathrm{mrs}$ \\
\hline 10 obradas de tierra de pan & Labajos (Segovia) & $5750 \mathrm{mrs}$ \\
\hline 6 obradas de forañas & Labajos (Segovia) & $600 \mathrm{mrs}$ \\
\hline 8 obradas y $1 / 2$ de forañas & Labajos (Segovia) & $2975 \mathrm{mrs}$ \\
\hline $\begin{array}{c}1 \text { obrada que linda con tierras } \\
\text { de Fernando Núñez }\end{array}$ & Labajos (Segovia) & $1405 \mathrm{mrs}$ \\
\hline 10 obradas de tierras de pan & Labajos (Segovia) & $5750 \mathrm{mrs}$ \\
\hline
\end{tabular}

Compras de María de Ávila

\begin{tabular}{|c|c|c|}
\hline BIEN & LUGAR & PRECIO \\
\hline 9 obradas & Maello (Segovia) & $2250 \mathrm{mrs}$ \\
\hline 1 obrada & Maello (Segovia) & $300 \mathrm{mrs}$ \\
\hline $\begin{array}{l}16 \text { obradas de tierras de pan, un linar, un } \\
\text { solar de casas y demás bienes raíces }\end{array}$ & $\begin{array}{c}\text { Mediana y su } \\
\text { Término (Ávila) }\end{array}$ & $7000 \mathrm{mrs}$ \\
\hline $\begin{array}{c}\text { Toda la heredad y bienes raíces } \\
\text { (del regidor abulense Vlasco Núñez Vela) }\end{array}$ & $\begin{array}{l}\text { Mediana y Rebilla } \\
\text { (Ávila) }\end{array}$ & $63000 \mathrm{mrs}$ \\
\hline $\begin{array}{c}\text { Media yugada de heredad, } \\
\text { con parte de los prados }\end{array}$ & $\begin{array}{c}\text { La Solana de } \\
\text { Pero Abad (Ávila) }\end{array}$ & $9000 \mathrm{mrs}$ \\
\hline $\begin{array}{c}\text { Un portillo de heredad, otra heredad: tierras } \\
\text { de pan, casas, solares de casas, prados, pas- } \\
\text { tos, montes, ejidos, aguas etc }\end{array}$ & $\begin{array}{l}\text { Mediana, Rebilla, } \\
\text { Pero Abad (Ávila) }\end{array}$ & $\begin{array}{c}\text { Acuerdo arbitral: } 37000 \\
\text { mrs }\end{array}$ \\
\hline $\begin{array}{c}\text { Traspasamiento de censos sobre dehesa, he- } \\
\text { redamiento y bienes raíces }\end{array}$ & $\begin{array}{c}\text { Boltoyuela, cerca de } \\
\text { Mediana (Ávila) }\end{array}$ & $\begin{array}{c}\text { Censo perpetuo cada año } \\
100 \mathrm{mrs}\end{array}$ \\
\hline $\begin{array}{c}\text { Dehesa y heredamiento con: prados, pastos, } \\
\text { tierras de labranza, eras, montes, solares, } \\
\text { ejidos, abrevaderos, valles, aguas etc }\end{array}$ & $\begin{array}{l}\text { Boltoyuela, cerca de } \\
\text { Mediana (Ávila) }\end{array}$ & $100000 \mathrm{mrs}$ \\
\hline $\begin{array}{c}\text { Todas las heredades y bienes raíces de } \\
\text { Pedro de Ávila }\end{array}$ & Mediana y Rebilla & $800 \mathrm{mrs}$ \\
\hline $\begin{array}{l}\text { Cuarta parte de una heredad con todos sus } \\
\text { bienes anexos: casas y solares de casas, tie- } \\
\text { rras de pan, linares, prados, pastos, ejidos, } \\
\text { aguas con todos sus usos y costumbres }\end{array}$ & $\begin{array}{c}\text { Ávila } \\
\text { (sin especificar) }\end{array}$ & $2000 \mathrm{mrs}$ \\
\hline Heredad y bienes raíces & $\begin{array}{l}\text { Mediana y Rebilla } \\
\text { (Ávila) }\end{array}$ & $6000 \mathrm{mrs}$ \\
\hline 1 molino & Pero Abad (Ávila) & 19000 mrs. \\
\hline
\end{tabular}


Compras de Fernando de Acuña y María de Ávila

\begin{tabular}{|c|c|c|}
\hline BIEN & LUGAR & PRECIO \\
\hline 10 obradas & Labajos (Segovia) & $2766 \mathrm{mrs}$ \\
\hline 5 obradas & Labajos (Segovia) & $1500 \mathrm{mrs}$ \\
\hline 10 obradas & Labajos (Segovia) & $2766 \mathrm{mrs}$ \\
\hline 10 obradas & Labajos (Segovia) & $2766 \mathrm{mrs}$ \\
\hline $1 / 2$ yugada de heredad & $\begin{array}{c}\text { La Solana } \\
\text { de Pero Abad (Ávila) }\end{array}$ & $9500 \mathrm{mrs}$ \\
\hline Bienes raíces, con prados, eras, aguas etc & Pero Abad (Ávila) & $800 \mathrm{mrs}$ \\
\hline Unas casas tejadas & Mediana (Ávila) & $7500 \mathrm{mrs}$ \\
\hline 5 obradas & Labajos (Segovia) & $1383 \mathrm{mrs}$ \\
\hline 5 obradas & Labajos (Segovia) & $1383 \mathrm{mrs}$ \\
\hline 7 obradas y $1 / 2$ & Labajos (Segovia) & $2075 \mathrm{mrs}$ \\
\hline 7 obradas y $1 / 2$ & Labajos (Segovia) & $2075 \mathrm{mrs}$ \\
\hline 5 obradas & Labajos (Segovia) & $1100 \mathrm{mrs}$ \\
\hline 8 obradas y $1 / 2$ & Labajos (Segovia) & $2300 \mathrm{mrs}$ \\
\hline 15 obradas & Labajos (Segovia) & $4150 \mathrm{mrs}$ \\
\hline $\begin{array}{l}\text { Una heredad con prados, casas, } \\
\text { solares de casas etc }\end{array}$ & Pero Abad (Ávila) & Sin datos \\
\hline $1 / 2$ yugada de heredad & Labajos (Segovia) & $8300 \mathrm{mrs}$ \\
\hline 7 obradas y $1 / 2$ & Labajos (Segovia) & $2070 \mathrm{mrs}$ \\
\hline 7 obradas y $1 / 2$ & Labajos (Segovia) & $2000 \mathrm{mrs}$ \\
\hline 7 obradas y $1 / 2$ & Labajos (Segovia) & $2000 \mathrm{mrs}$ \\
\hline 7 obradas y $1 / 2$ & Labajos (Segovia) & $2000 \mathrm{mrs}$ \\
\hline 7 obradas y $1 / 2$ & Labajos (Segovia) & $2000 \mathrm{mrs}$ \\
\hline 15 obradas & Labajos (Segovia) & $4000 \mathrm{mrs}$ \\
\hline
\end{tabular}

Compras de Fernando de Acuña en Segovia

\begin{tabular}{|l|c|c|}
\hline \multicolumn{1}{|c|}{ BIEN } & LUGAR & PRECIO \\
\hline 1 obrada 1 1/2 foraña & Maello (Segovia) & $375 \mathrm{mrs}$ \\
\hline 6 obradas & Labajos (Segovia) & $2000 \mathrm{mrs}$ \\
\hline 15 obradas & Labajos (Segovia) & $4150 \mathrm{mrs}$ \\
\hline 15 obradas & Labajos (Segovia) & $4150 \mathrm{mrs}$ \\
\hline 5 obradas & Labajos (Segovia) & $1383 \mathrm{mrs}$ \\
\hline 12 obradas & Labajos (segovia) & $2600 \mathrm{mrs}$ \\
\hline 5 obradas & Labajos (Segovia) & $1100 \mathrm{mrs}$ \\
\hline 5 obradas & Labajos (Segovia) & $1383 \mathrm{mrs}$ \\
\hline
\end{tabular}

